
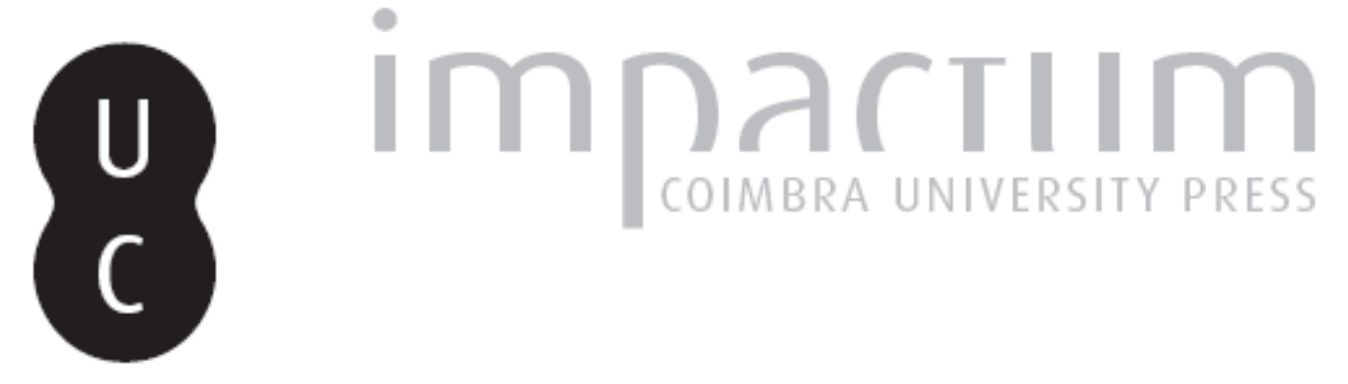

\title{
Problemáticas históriças e arquivísticas actuais para o estudo dos arquivos de família portugueses (Épocas Medieval e Moderna)
}

\author{
Autor(es): $\quad$ Rosa, Maria de Lurdes \\ Publicado por: Centro de História da Sociedade e da Cultura \\ URL \\ persistente: \\ URI:http://hdl.handle.net/10316.2/39576 \\ DOI: \\ DOI:http://dx.doi.org/10.14195/1645-2259_9_1
}

Accessed : $\quad$ 26-Apr-2023 12:56:23

A navegação consulta e descarregamento dos títulos inseridos nas Bibliotecas Digitais UC Digitalis, UC Pombalina e UC Impactum, pressupõem a aceitação plena e sem reservas dos Termos e Condições de Uso destas Bibliotecas Digitais, disponíveis em https://digitalis.uc.pt/pt-pt/termos.

Conforme exposto nos referidos Termos e Condições de Uso, o descarregamento de títulos de acesso restrito requer uma licença válida de autorização devendo o utilizador aceder ao(s) documento(s) a partir de um endereço de IP da instituição detentora da supramencionada licença.

Ao utilizador é apenas permitido o descarregamento para uso pessoal, pelo que o emprego do(s) título(s) descarregado(s) para outro fim, designadamente comercial, carece de autorização do respetivo autor ou editor da obra.

Na medida em que todas as obras da UC Digitalis se encontram protegidas pelo Código do Direito de Autor e Direitos Conexos e demais legislação aplicável, toda a cópia, parcial ou total, deste documento, nos casos em que é legalmente admitida, deverá conter ou fazer-se acompanhar por este aviso.

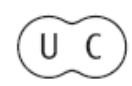



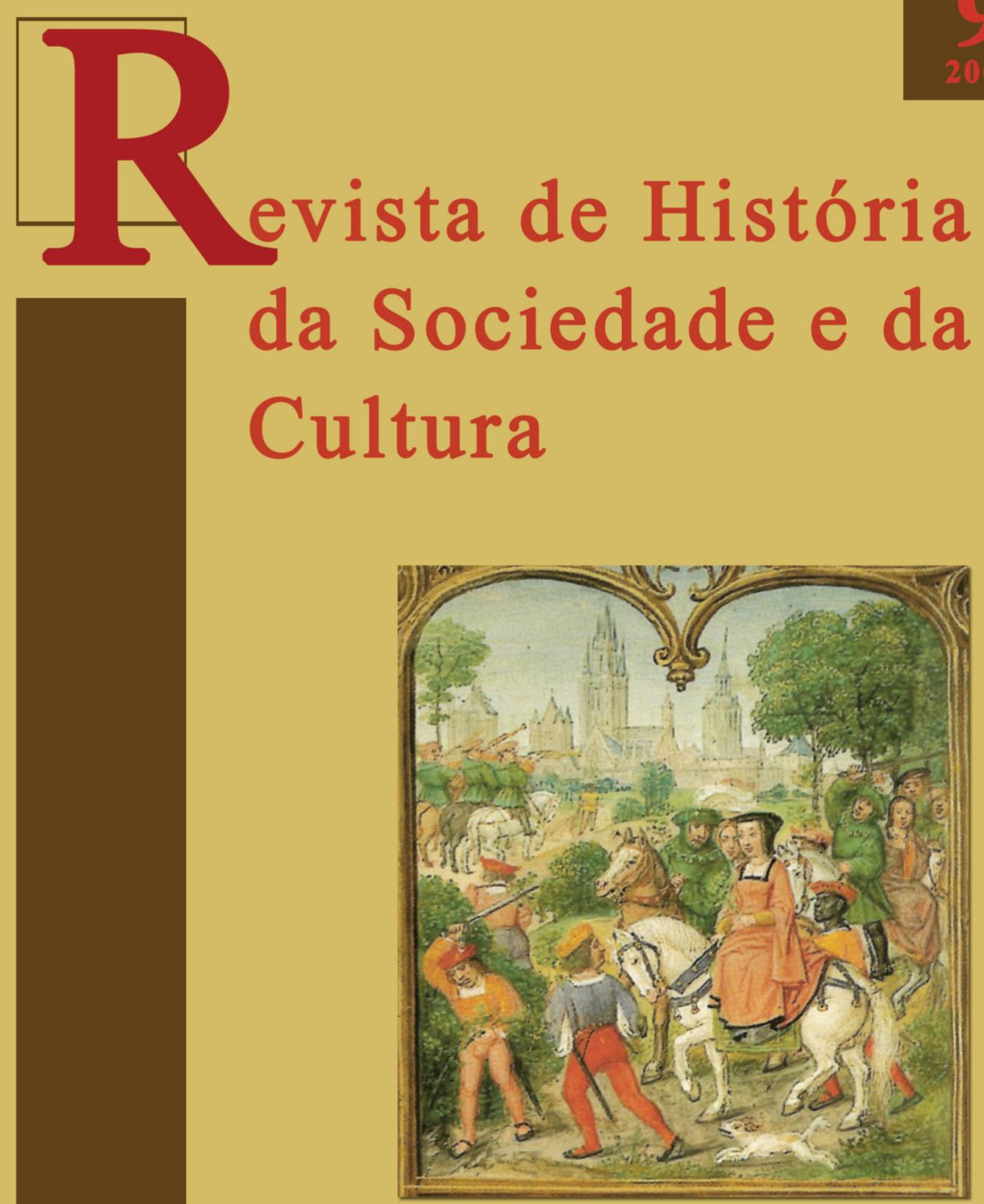

Centro de História da Sociedade e da Cultura Universidade de Coimbra

Coimbra 


\title{
Problemáticas históricas e arquivísticas actuais para o estudo dos arquivos de família portugueses (Épocas Medieval e Moderna)
}

\author{
Maria de Lurdes Rosa \\ Departamento de História da FCSH da Universidade Nova de Lisboa \\ e Instituto de Estudos Medievais \\ mlrosa@fcsh.unl.pt
}

Texto entregue em/Text submited on: 16/04/2009

\section{Resumo/Abstract:}

Os arquivos de família são conjuntos documentais de notável interesse, tanto para a História como para a arquivística. Tenta-se aqui de apresentar vias de estudo destes acervos no âmbito das duas disciplinas, tanto em termos de dados objectivos, como dos aspectos ligados à estrutura da informação. O texto situa-se na confluência dos saberes historiográfico e arquivístico, sendo este último perspectivado a partir da renovação de paradigma epistemológico da ciência da informação. Na primeira parte, apresentam-se campos de inovação teórica que possibilitam um mais frutuoso diálogo entre os dois saberes. De seguida, aborda-se a temática da revalorização dos arquivos de família, em Portugal, França, Espanha e Itália. Por fim, propõe-se uma primeira aproximação, em função das ideias expostas, a um importante acervo familiar depositado no ANTT, cuja descrição foi recentemente disponibilizada em linha - o Arquivo dos Viscondes de Vila Nova de Cerveira.

Family archives are sources of remarkable interest for both history and archivistics. The study methods of this acquis under these two disciplines are described herein, either in terms of the objective data, or of the structure of the information. This paper places itself at the crossroad of historiographic and archivistic knowledge, the latter being viewed from the perspective of the renewed epistemological paradigm of information science. The first part introduces fields of theoretical innovation that foster a fruitful dialogue between the two subjects. Then it discusses the enhancement of the value of family archives, in Portugal, France, Spain and Italy. Finally, the paper proposes a primary approach to an important acquis deposited at the Torre do Tombo national archive, the description of which was recently published on line: the Archive of the Viscounts of Vila Nova de Cerveira.

\section{Palavras chave/Key words:}

História; Arquivística; Arquivos de Família; Viscondes de Vila Nova de Cerveira.

History; Archivistics; Family archives; the Viscounts of Vila Nova de Cerveira. 


\section{Introdução}

Tem-se assistido, nas últimas décadas, a diversos movimentos de renovação dos campos historiográfico e arquivístico - e referimo-nos aqui à arquivística enquanto "ciência da informação" -, que oferecem estimulantes perspectivas no tema em análise. O presente artigo tem como objectivo apresentar as principais linhas destes movimentos, bem como tentar uma brevíssima aplicação de parte dos novos paradigmas a um arquivo de família concreto, depositado no Arquivo Nacional da Torre do Tombo, cuja descrição já se encontra disponível em linha. Neste momento, dado a recente disponibilização do acervo, far-se-á apenas uma aproximação preliminar ao mesmo, que no futuro será trabalhado de forma global ${ }^{2}$. As problemáticas histórica e arquivística podem, contudo, desde já ser apresentadas de forma ampla, dada a riqueza bibliográfica das últimas décadas, em diferentes tradições europeias e norte-americanas, e a similitude dos temas e problemas em jogo. Parte-se, portanto, destas, para sugerir vias novas de abordagem aos acervos portugueses, num âmbito comparativo.

A perspectiva será não tanto a do arquivista, ou cientista da Informação, mas sim a do historiador - mesmo que estudioso de história dos arquivos -, porém, sempre em diálogo com os investigadores daquela primeira área, em plano de igualdade. É de facto necessário ultrapassar o que os cientistas da informação chamam de "paradigma historicista", ou seja, um olhar para os arquivos/“sistemas de informação" apenas a partir dos dados deles extraíveis para resposta a um inquérito historiográfico - perspectiva instrumentalista que foi acompanhada de outras subalternizações, a começar por uma relação

1 Dispomos em Portugal de uma actualizada reflexão sobre o assunto, para a qual remetemos: SILVA, Armando Malheiro; RIBEIRO, Fernanda; RAMOS, Júlio e REAL, Manuel Real - Arquivística: teoria e prática de uma ciência da informação. Porto: Ed. Afrontamento, 1998, vol. 1; SILVA, Armando Malheiro; RIBEIRO, Fernanda-Das "ciências" documentais à ciência da informação. Ensaio epistemológico para um novo modelo curricular. Porto: Ed. Afrontamento, 2008, $2^{\text {a }}$ ed.; SILVA, Armando Malheiro da - A Informação. Da compreensão do fenómeno e construção do objecto científico. Porto: Ed. Afrontamento;CETAC, 2006. Uma boa introdução sobre a renovada "archival science" pode ver-se em THOMASSEN, Theo - A First Introduction to Archival Science. Archival Science. 1 (2001) 73-85.

2 Este artigo insere-se nos trabalhos de um projecto de pós-doutoramento intitulado "Em torno dos arquivos de família do Portugal Medieval e Moderno. Ciência arquivística, História social e património", financiado pela FCT. 
de poder científico (?): a história como ciência nobre, a arquivística como "ciência auxiliar" (ou, mesmo, apenas "técnica"). Ora, mesmo considerando apenas o historiador, aparentemente o parceiro vencedor da sociedade, esta posição não só pode levar a uma visão distorcida da informação coeva (a sua constituição em "fonte", de modo absoluto), como deixa para trás elementos importantes ao raciocínio histórico: as vicissitudes sofridas pelos dados que nos chegam do passado, o lugar que estes ocupavam no sistema de informação global em que foram produzidos e, por fim, a forma como são mediatizados pelos instrumentos de descrição documental, a partir do início, ou seja, a natureza e a constituição dos "arquivos públicos". Muito mais do que enriquecimentos de conteúdos - embora tal não seja negligenciável, temos que resistir à tentação parasitária do historiador sobre a informação do passado -, as novas perspectivas vêm permitir um enriquecimento dos percursos de investigação, que conduzirá, em última análise, tanto a uma requalificação da informação antiga, como a interrogações do trabalho historiográfico que poderão ajudá-lo a tornar-se menos anacrónico e mais livre de deformações insuspeitas.

\section{Campos de inovação e de diálogo}

\subsection{Informação e sistemas de informação $v s$ "fontes"/"corpus documentais"/arquivos}

Um primeiro aspecto da moderna arquivística, com importância conceptual e metodológica para a prática historiográfica, é a constituição da "informação" como o seu objecto central de estudo, bem como de uma forma específica desta, o sistema de informação social que é o arquivo: “Arquivo é um sistema (semi-)fechado de informação social materializada em qualquer tipo de suporte, configurado por dois factores essenciais - a natureza orgânica (estrutura) e a natureza funcional (serviço/uso) - a que se associa um terceiro - a memória - imbricado nos anteriores"3. Os dados que nos chegam do

3 SILVA, Armando Malheiro da Silva e outros - Arquivística: teoria e prática..., cit., p. 214. 
passado foram informação, e não "documentos" ou "fontes"; produzidos por uma instituição (mesmo que o uso não anacrónico deste conceito obrigue a falar de "coisas" muito pouco institucionais à luz da institucionalidade inaugurada com o Estado liberal), eles dependem da natureza e da estrutura dessa instituição, antes de tudo o mais ${ }^{4}$. Dependem, de seguida, da forma como no seio da mesma se conservava a informação produzida, e como ao longo dos séculos esta relação se processou - desde logo, com ou sem influências desestruturantes exteriores (com estas influências é, em geral, o caso da maioria dos fundos presentes nos arquivos públicos).

Sem dúvida que o inquérito continua a ser uma etapa essencial do processo historiográfico: o passado configura-se para o historiador em função de determinado conjunto de interrogações, alicerçado em teoria e em historiografia. A valorização da etapa prévia, pode, porém, introduzir toda a diferença. Os vestígios do passado não são apenas as "fontes" para resposta ao inquérito historiográfico. É necessária uma reconsideração integral da informação do passado que chegou até nós, vista como um sistema em si, que tem de ser tomado em conta mesmo quando se abordam apenas aspectos parciais. Entre outras coisas, a posição de um documento no local exacto do sistema de informação que o produziu, bem como a natureza desse sistema de informação, condicionam obviamente a informação que ele transmite. Recorrendo a um exemplo estudado ultimamente numa reconsideração da "economia mendicante" medieval, as informações "económicas" dos documentos dos conventos mendicantes não são "apenas números", nem os documentos que as registam são folhas de contabilidade modernas, que se podem sem problemas transferir para folhas de cálculo e bases de dados (no que resulta na por vezes perversa criação de um autêntico ecrã opaco,

${ }^{4}$ Estas questões são hoje em dia alvo de interessantes debates pelos próprios arquivistas, que no seu essencial revêem utilizações simplistas do "princípio da proveniência" e do respeito pela ordem original, sem rejeitar totalmente o uso dos conceitos, mas revisitando-os: LODOLINI, Elio - Respect des fonds et principe de provenance. Histoire, théories, pratiques. Gazette des archives. 168 (1995) 11-163; EDWARDS, Robert - «With Respect to Original Order»: Changing Values in Archival Arrangement. AABC Newsletter. 11/1 (Winter 2001); HORSMAN, Peter - The Last Dance of the Phoenix, or The De-discovery of the Archival Fonds. Archivaria. 54 (Fall 2002), 1-23; HORSMAN, Peter; KETELAAR, THOMASSEN, Theo - New Respect for the Old Order: The Context of the Dutch Manual. The American Archivist. 66 (Winter/Spring 2003) 249-270. 
que ganha sentido em si, mesmo sendo totalmente anacrónico). Aquelas informações requerem uma descodificação em função da sua proveniência de instituições (conventos) que têm determinada relação com a posse de bens, que alicerçam grande base dos seus "rendimentos" em recolha de esmolas e "entregas" de "amigos", que aplicam os "lucros" em objectivos não materiais e que, finalmente, registam de formas diversas todas estas operações. Aliás, as famosas "fontes subsistentes" podem ser em grande parte condicionadas por factores desta natureza - não restarem documentos relativos às campanhas de esmolas ou ofertas de amigos não quer dizer que elas não tivessem grande importância na economia dos conventos mendicantes 5 .

É preciso portanto um exercício rigoroso de reconstituição da orgânica produtora de documentação, para avaliarmos não o que resta mas porque resta (podendo não ser o mais importante para o inquérito); e o que não resta, e também porquê $\hat{e}^{6}$. A par destas operações, a reconstituição dos contextos

5 Pontos da situação em CHIFFOLEAU, Jacques - Pour une économie de l'institution ecclésiale à la fin du Moyen-Âge. Mélanges de l'École française de Rome, Moyen-Âge Temps modernes. 96 (1984) 247-279; CHIFFOLEAU, Jacques - Usus pauper? Notes sur les franciscains, la Règle et l'argent en Avignon entre 1360 et 1480 in Horizons marins, itinéraires spirituels. Paris: Publ. de la Sorbonne, 1987, vol. 1, 135-147; CHIFFOLEAU, Jacques - Conclusions. Les couvents, l'échange et la religion in L'economia dei conventi dei frati minori e predicatori fino alla metà del Trecento. Atti del XXXI Convengo internazionale. Assisi, 9-11 ottobre 2003. Espoleto: CISAM, 2004, p. 405-448. Estas abordagens inserem-se numa corrente mais vasta de reconsideração da economia medieval, nomeadamente na relação entre bens materiais e espirituais, que começou pelo uso do conceito de dom, para a economia alto-medieval e que agora tem prosseguido com a aplicação do mesmo na época tardo-medieval e mesmo posterior, cortando, entre outras coisas anacrónicas, com a "modernidade mendicante", cf. entre os mais significativos, para além dos pioneiros LITTLE, LESTER - Religious poverty and the profit economy in medieval Europe. Ithaca: Cornell UP, 1978 e TODESCHINI, Giaccomo - Oeconomia francescana. Proposte per una lettura dele fonti dell'etica economica medievale. Rivista di Storia e letteratura religiosa. XII/1 (1976) 15-77; GUERREAU-JALABERT, Anita- Caritas y don en la sociedad medieval occidental. Hispania. vol LX/I (2000), 27-62 e BASCHET, Jérôme - La civilisation féodale. De l'an mil à la colonisation de l'Amérique. Paris: Flammarion, 2006, $3^{\text {a }}$ ed. revista, p. 489 e seguintes e 582 e seguintes.

$6 \mathrm{ESCH}$, Arnold - Chance et hasard de transmission. Le problème de la représentativité et de la déformation de la transmission historique in SCHMITT, J.-Cl. ; OEXLE, Otto G. (dir.) - Les tendances actuelles de l'histoire du Moyen-Âge en France et en Allemagne. Paris: Publ. de la Sorbonne, 2001, p. 15-29 e SCHMITT, J.-Cl. - Une réflexion nécessaire sur le document in SCHMITT, J.-Cl. ; OEXLE, Otto G. (dir.) - Les tendances ..., cit., p. 43-46. 
históricos mantém-se fundamental, tanto mais importante em sociedades que assentem em ordenamentos globais diversos do contemporâneo ${ }^{7}$.

É justo referir, ainda que brevemente, dados os limites do artigo, que a reflexão historiográfica sobre o seu material de trabalho tem incidido cada vez mais sobre estas problemáticas, mesmo se o diálogo com as "ciências da Informação" se tem revelado moroso. Bastar-nos-ia lembrar a proposta de Jacques Le Goff do "documento/monumento", na qual se destaca o carácter construído do "documento", a partir da erudição iluminista"; mas seria injusto deixar de parte alguns avanços recentes, como seja a interrogação da noção de fonte a que procedem, por exemplo, Joseph Morsel e Ludolf Kuchenbuch ${ }^{9}$. Todos estes contributos e, sobretudo, o regresso a uma interrogação profunda dos fundamentos empíricos do labor historiográfico, como atitude a contrapor ao afã monográfico e neo-positivista, contribuirão decisivamente, sem dúvida, para um diálogo enriquecedor entre a História e as Ciências da Informação.

\subsection{A mediação da informação}

Não menos fundamental é a interrogação da arquivística contemporânea sobre dois grandes mediadores da informação: o arquivo público e o instrumento de descrição documental. Em França, Itália, Espanha, e Portugal tem sido estudado de forma aprofundada e sugestiva, na última década, o nascimento dos "arquivos nacionais", em obras de grande qualidade para

${ }^{7}$ KOSELlECK, R. - Le futur passé. Contributions à la sémantique des temps historiques. Paris: Ed. EHESS, 1990; GUERREAU, Alain - Fief, féodalité, féodalisme. Enjeux sociaux et réflexion historienne. Annales ESC. 45 (1990) 137-166; GUERREAU, Alain - L'avenir d'un passé incertain. Quelle histoire du Moyen-Âge au XXIe. siècle?, Paris: Du Seuil, 2001.

8 LE GOFF, Jacques - Documento/monumento in Memória-História. Enciclopédia Einadi. Lisboa: IN-CM, 1984, vol. 1, 95-106.

9 MORSEL, Joseph - Les sources sont-elles le pain de l'historien?. Hyphotèses. Travaux de l'École doctorale de Paris I. 1 (2003) 271-286; KUCHENBUCH, Ludolf - Sources ou documents? Contribution à l'histoire d'une évidence méthodologique. Hyphotèses. Travaux de l'École doctorale de Paris I. 1 (2003) 287-315. 
as quais remetemos para as grandes linhas do processo ${ }^{10}$. Existem cada vez mais, além disto, estudos sobre um instrumento de trabalho que para muitos historiadores quase não existe, mas que o arquivista informado sabe bem que pode condicionar totalmente a visão daqueles - os IDD's, sigla para “instrumento de descrição documental". Para Portugal, é representativo desta tendência o trabalho de Fernanda Ribeiro ${ }^{11}$, onde se analisam os instrumentos de descrição documental disponíveis no sistema arquivístico português até meados da década de 90 do século XX, inserindo-os numa evolução histórica dos diversos sistemas de informação existentes desde a Época Medieval. Na mesma senda, o estudo da autora sobre a estrutura primitiva da Casa do Coroa, é claro quanto aos problemas que encerram os IDD's disponíveis para a "documentação" que resta desta estrutura/instituição (de resto, interrogável enquanto tal), desde a natureza que se atribuiu ao acervo, até às divisões orgânicas propostas ${ }^{12}$.

A reflexão sobre a estrutura dos IDD's é de facto muito importante ${ }^{13}$. Para além de serem a primeira porta no acesso à informação do passado custodiada em serviços de arquivo histórico, eles deveriam ser também

${ }^{10}$ GENERELO, Juan José; MORENO LÓPEZ, Angelo (coord.) - Historia de los archivos y de la archivistica en España. Valladolid: Universidad de Valladolid, 1998; DELMAS, B.; Ch. NOUGARET (dir.) - Archives et nations dans l'Europe du XIXe siècle. Paris: École Nationale des Chartes, 2004; Archivi e storia nell'Europa del XIX secolo. Roma: Ministerio per i Beni Culturali, 2006, 2 vol.; SILVA, Armando Malheiro da Silva e outros - Arquivística: teoria e prática ..., cit., p. 100 e seguintes; RIBEIRO, Fernanda - O acesso à informação nos arquivos. Lisboa, FCG;FCT, 2003, vol. 1, p. 401 e seguintes; RIBEIRO, Fernanda - Para o estudo do paradigma patrimonialista e custodial. A Inspecção das Bibliotecas e Arquivos e o contributo de António Ferrão (1887-1965), Porto: CETAC; Ed. Afrontamento, 2008; não exactamente sob o mesmo prisma, mas pioneiros na temática, foram os artigos de José Mattoso sobre o Arquivo Nacional, reunidos em MATTOSO, José - A escrita da História. Teoria e métodos. Lisboa: Estampa, 1988, p. 65 e seguintes.

${ }^{11}$ RIBEIRO, Fernanda - $O$ acesso..., cit..

${ }^{12}$ RIBEIRO, Fernanda - Como seria a estrutura primitiva do Arquivo da Casa da Coroa (Torre do Tombo) in FONSECA Luís Adão da (coord.) - Os reinos ibéricos na Idade Média: livro de homenagem ao Professor Doutor Humberto Carlos Baquero Moreno. Porto: Civilização, 2003, vol. III, p. 1401-1414.

${ }^{13}$ Como pensamos cabalmente demonstrado pelo estudo de RIBEIRO, Fernanda O acesso..., cit., p. 691. Aqui se equaciona a relação desigual de poder que existe entre um arquivista como produtor de instrumentos de acesso para o historiador, e este último, produtor de explicações científicas, e sugerem-se formas de redefinição do papel do primeiro a partir da questão dos "instrumentos de acesso", formas essas potencialmente geradoras de relações diversas mas mais respeitadoras do trabalho de ambos. 
estudos que enriquecessem as nossas concepções sobre as passadas formas de relação com a memória histórica e com a administração documental. Para que isto seja possível, é necessário um grande investimento na investigação em história institucional (não anacrónica, isto é, configurando as instituições a partir dos contextos históricos) $)^{14} \mathrm{e}$ em história da arquivística. É com toda a justiça que se tem ultimamente criticado e rejeitado os "quadros de classificação temático-funcionais", que podem ser verdadeiramente prejudiciais no que toca aos arquivos antigos ${ }^{15}$. No caso português, eles foram e são tanto mais perigosos quanto surgiram num panorama de grande penúria de descrições documentais - mesmo ao nível das mais elementares - e pareceram vir proporcionar uma organização inteligente e compreensível da documentação, situada a enorme distância das listas, guias de remessas e ficheiros, dos mais arcaicos, que abundavam pelos arquivos públicos.

${ }^{14}$ Em Portugal devem destacar-se a este respeito os trabalhos de António Hespanha, desde a colectânea por si organizada HESPANHA, A.M. - Poder e instituições na Europa de Antigo Regime. Lisboa: FCG, 1984, p.7-89, a temas vários, interessando-nos aqui a família, no que foi uma ultrapassagem nítida a considerações estreitamente jurisdicistas do âmbito institucional desta HESPANHA, A. M. - Carne de uma só carne: para uma compreensão dos fundamentos histórico-antropológicos da família na Época Moderna. Análise Social. XXVIII, 123-124 (1993) 951-973. Também importantes, porque informativas, mas em geral com uma contextualização bastante pobre GACTO, Enrique - El marco juridico de la familia castellana. Edad Moderna. Historia. Instituciones. Documentos. 11 (1985) 37-66. Na década de 90 do século XX seguiram-se outros importantes trabalhos de contextualização de instituições até então estudadas de forma tradicional, em especial a Coroa: CARDIM, Pedro - O poder dos afectos. Ordem amorosa e dinâmica política no Portugal do Antigo Regime. Lisboa: [s. n.], 2000 (dissertação de doutoramento em História apresentada à FCSH da Universidade Nova de Lisboa); CURTO, Diogo Ramada - A cultura política em Portugal (1578-1642): comportamentos, ritos e negócios. Lisboa: [s. n.] dissertação de doutoramento em História apresentada à FCSH da Universidade Nova de Lisboa); tentámos uma caracterização não anacrónica das capelas fúnebres enquanto instituições de Antigo Regime em ROSA, Maria de Lurdes - "As almas herdeiras". Fundação de capelas fúnebres e afirmação da alma como sujeito de direito (Portugal, 1400-1521). Lisboa: [s. n.], 2005 (dissertação de doutoramento em História apresentada à École des Hautes Études en Sciences Sociales (Paris) e FCSH da Universidade Nova de Lisboa). Os trabalhos de Bartolomé Clavero são fundamentais neste âmbito, ver CLAVERO, Bartolomé - Antidora. Antropologia Catolica de la Economia Moderna. Milão: Giuffrè Editore, 1991.

${ }^{15}$ Ver a importante análise crítica de SILVA, Armando Malheiro da-Arquivos de família e pessoais. Bases teórico-metodológicas para uma abordagem científica. in Arquivos de família e pessoais. Seminário. Vila Real: BAD, 1997, p. 51-106, e SILVA, Armando Malheiro da - Arquivos familiares e pessoais. Bases científicas para aplicação do modelo sistémico e interactivo. Revista da Faculdade de Letras. Ciências e técnicas do património. III (2004) $55-84$. 
Foram difundidos alguns, para várias tipologias de arquivos, que, apesar das virtudes que possam deter, de pronto começaram a funcionar como verdadeiras receitas de arrumação da documentação, mesmo para quem não seja arquivista. Nos trabalhos relativos a alguns sistemas depositados em arquivos públicos, imperam os quadros temático-funcionais, alguns difundidos urbi et orbi (arquivos municipais, de confrarias, de ordens religiosas, de famílias) ${ }^{16}$. Em variadíssimos IDD's, as divisões orgânicas das mais diversas instituições, e/ou listas de séries, são apresentadas sem que se indiquem as bases do seu estabelecimento e sem os imprescindíveis estudos de história institucional e arquivística. Em alguns casos, adoptar uma estrutura de descrições em catálogo cronológico seria preferível à inserção errónea da documentação em secções, cuja fundamentação é incerta ou omitida. Seria importante uma reflexão sobre o assunto, de modo a poder-se aproveitar as virtudes das novas práticas, evitando, porém, o excessivo simplismo.

\subsection{A importância da investigação científica em "arquivística histórica"}

Os cientistas da informação têm argumentado que a configuração institucional do exercício da sua profissão está, em parte, na raiz do problema ${ }^{17}$.

${ }^{16}$ Referimo-nos ao Recenseamento dos arquivos locais: câmaras municipais e misericórdias. Inventário do Património Móvel, coord. geral José Mariz, 16 vols. Lisboa: Arquivos Nacionais/Torre do Tombo, 1995, cujo quadro de classificação, para os arquivos municipais, tem hoje em dia uma aplicação quase total, como se pode ver nos sítios informáticos dos arquivos municipais; o modelo deste quadro foi elaborado no Instituto Português de Arquivos, MARIZ, José - Quadro de classificação dos arquivos municipais. Lisboa: I.P.A., 1989. Seria interessante verificar o que se passa neste momento com os arquivos das confrarias. Muitos dos fundos descritos no Guia de Fundos da Torre do Tombo, seguem quadros afins, ou não explicitam a forma de construção dos quadros utilizados, ver Guia geral dos fundos da Torre do Tombo. Lisboa: ANTT, 1998-2005, 6 vol.. Não pretendemos aqui desmerecer a importância de todo este trabalho que, como referimos, sucedeu a um enorme vazio e a um grande atraso em relação a outras práticas arquivísticas europeias. No entanto, cremos que se poderia agora passar a investir em trabalhos de adequação histórica destes quadros. É certo, porém, que nem sempre é fácil seguir esta opção, como nos próprios serviços dedicados a arquivos de família se tem constatado.

${ }^{17}$ SILVA, Armando Malheiro e outros - Arquivistica ..., cit., p. 11-12 e 172 e seguintes; e, em especial; SILVA, Armando Malheiro; RIBEIRO, Fernanda - Das "ciências" documentais..., cit., capítulo 4. 
Os arquivistas não são investigadores, mas produtores de trabalho para os serviços de administração ou de custódia dos documentos. É bem verdade que a organização dos acervos está muito dependente da pressão dos detentores destes. $\mathrm{O}$ trabalho que realizámos nos últimos anos num sector bem menos sujeito aos problemas de apresentação de resultados que têm os arquivos históricos públicos - o dos arquivos eclesiásticos - deparou sempre com esta solicitação ansiosa, por parte dos proprietários dos acervos. O estudo minucioso da instituição e dos sistemas de arquivagem no Instituto Português de Santo António, em Roma, foi encarado como uma tarefa menor pela administração da instituição, que queria "os papéis" rapidamente arrumados, em categorias "simples e que todos percebessem"18. Já por parte das autoridades diocesanas, o pedido permanente e insistente era o de um "quadro de classificação" fácil e simples, que se adaptasse a todas as dioceses e à sua documentação de todas as épocas. É justo mencionar a diferença que constituiu a enorme paciência do bispo de Cochim e a possibilidade de trabalho de investigação institucional facultada pela Fundação Calouste Gulbenkian, bem como a experiência de trabalho com os produtores da informação, a que não faltou o auxílio do próprio chanceler da diocese, elucidando em inúmeros pontos difíceis de um circuito documental diocesano eclesiástico e civil muito complexo ${ }^{19}$. Se é ainda raro que se alcancem condições de trabalho assim, tal tem também a ver com a forma técnica como é encarado o labor da organização e descrição documental, não se lhe conferindo tempo nem estruturas científicas para um salto qualitativo, que passa, sejamos claros, pela investigação institucional e

${ }^{18}$ ROSA, Maria de Lurdes - Santo Antonio dei Portoghesi: Elementos para a história do hospital nacional português em Roma (sécs.XIV-XX). Lusitania Sacra. $2^{\mathrm{a}}$ série, V (1993) 319-378.

${ }^{19}$ Os vários circuitos envolviam, desde logo, a diocese de Cochim, a Metrópole goesa, as autoridades eclesiásticas do reino (e, depois da República, com as vicissitudes das relações Estado/Igreja), as instituições leigas nacionais de suporte/controle missionário; num segundo círculo, Roma: o Papado, a Propaganda Fide, as Casas superiores das congregações religiosas e os organismos da Santa Sé a elas ligadas; por fim, dentro da diocese, as estruturas desta, os institutos religiosos, os movimentos laicais; e ainda a diocese na sua relação com as autoridades civis e eclesiásticas indianas e, antes, holandesas e inglesas. Sobre este projecto, quanto aos aspectos referido no texto, ver ROSA, Maria de Lurdes e outros - Arquivo Histórico da diocese de Cochim/Historical archives of the diocese of Cochin. Lisboa: Fundação Calouste Gulbenkian, 1995, p. 13-18. 
informacional. A cooperação universitária entre saberes pode ser aqui um passo fundamental, enquanto não estejam configurados ou consolidados assentos académicos próprios para as ciências da Informação.

A importância de acções neste âmbito é tanto maior quanto ele é um dos campos em que a arquivística contemporânea tem apresentado importantes novidades. A história da constituição, funcionamento e transmissão dos sistemas de informação afirma-se cada vez mais como etapa indispensável ao estudo da informação existente nas formas actuais dos mesmos - ou seja, a exigência de trabalhos de investigação arquivística para a constituição de quadros de classificação verdadeiramente orgânicos e dotados de espessura histórica. Cumpre referir, antes de apresentarmos alguns exemplos concretos no que toca aos arquivos de família, que estas preocupações vêm ao encontro de uma complexificação também do lado dos historiadores. Apenas nos campos mais directamente ligados ao tema em estudo, mencionem-se os avanços na valorização historiográfica do corpo linhagístico ${ }^{20}$, a par da interrogação do paradigma estatalista da História ${ }^{21}$. Aspectos possíveis da historicização da História, cada vez mais praticada de forma aprofundada ${ }^{22}$, revelam-se fundamentais para uma reconsideração do sistema total de produção, circulação e conservação da informação em sociedades de Antigo Regime.

${ }^{20}$ Referências ao estado da questão para o período medieval em BOISSELIER, Stéphane; SOUSA, Bernardo Vasconcelos - Pour un bilan de l'historiographie sur le Moyen Age portugais au XXe siècle. Cahiers de Civilization Médiévale. 49 (2006) 213-256; a este propósito deve ainda ver-se SOUSA, João Silva de - A casa senhorial em Portugal durante a Idade Média. Revista Portuguesa de História. 36/1 (2002-2003) 267-284; para a Época Moderna, PELÚCIA, Alexandra - Martim Afonso de Sousa e a sua linhagem: a elite dirigente do Império português nos reinados de D. João III e D. Sebastião, Lisboa: [s. n.], 2007 (dissertação de doutoramento em História apresentada à FCSH da Universidade Nova de Lisboa).

${ }^{21}$ CARDIM, Pedro - Centralização política e Estado na recente historiografia sobre o Portugal do Antigo Regime. Nação e Defesa. 2a série, 87 (Outono 1998) 129-158; HESPANHA, António M. - Pré-compréhension et savoir historique. La crise du modèle étatiste et les nouveaux contours de l'histoire du pouvoir. Rättshistorika Studier. XIX (1993) 49-67; SCHAUB, Jean-Frédéric - Le Temps et l'État: vers un nouveau régime historiographique de l'Ancien Régime Français. Quaderni Fiorentini per la Storia del Diritto. 25 (1996) 127-181; SCHAUB, Jean-Frédéric - Novas aproximações ao Antigo Regime português. Pénelope. 22 (2000) 119-140.

${ }^{22}$ OEXLE, Otto G. - L'historicisation de l'Histoire in OEXLE, Otto G. (dir.) - Les tendances..., cit., p. 31-41. 


\subsection{Para uma "história social dos arquivos": a colaboração entre cientistas da informação e historiadores}

A investigação em história dos arquivos/das instituições produtoras de documentação tem vindo a ser definida como fundamental por diversos estudiosos da arquivística enquanto ciência da informação, pelo menos desde a década de 80 do século $X^{23}$. Não se tratava mais dos estudos sobre instituições que precediam os IDD's, por alargados que fossem. Investigações aprofundadas sobre a produção, organização e conservação da informação histórica foram surgindo paulatinamente ${ }^{24}$, embora a um ritmo menor do que o da história das bibliotecas e sistemas de escrita, muito desenvolvido pela voga na New Cultural History, dos anos 70 em diante ${ }^{25}$. Apenas recentemente, no entanto, se têm realizado intersecções de perspectivas com os historiadores, para benefício de ambas as partes, em especial no que toca às formulações teóricas e à complexificação dos questionários.

Tomemos como acontecimento significativo duas recentes realizações, uma na Europa, outra nos EUA. A primeira é o número de 2004 da prestigiada Revue de Synthèse, dedicado ao tema "Fabrique des archives, fabrique de l'histoire". Só a formulação do título é significativa, numa tradição académica e cultural onde a História tem um papel de altíssima hegemonia

${ }^{23}$ GARCIA CUADRADO, Amparo - La investigación en história de las instituciones documentales: estudo de la investigación y propuesta metodológica. Anales de Documentación. 1 (1998) 55-74 e LÓPEZ GÓMEZ, Pedro - Archival science in Spain between 1975 and 2005: a review. Archival Science. 7 (2007) 245-287.

${ }^{24}$ RICHARD, J. - Les archives et les archivistes des ducs de Bourgogne dans le resort de la Chambre des Comptes de Dijon. Bibliothèque de l'Ecole de Chartes. CV (1944) 123-169; RÜCK, Peter - L'ordinamento degli archivi ducali di Savoia sotto Amedeo VIII: (1398-1451). Roma: 1977 (separata de Quaderni della Rassegna degli Archivi di Stato, 48); D'ADARIO, A. - L'inventariazione archivistica fra XVII e XIX secolo. Archiva Ecclesiae. Bolletino dell' Associazione Archivistica Ecclesiastica. 26-27 (1983-1984) 29-48; CABRILLANA CIEZAR, Nicolas - Archivos familaires malagueños del siglo XVI. Archivo hispalense. $2^{\mathrm{a}}$ época, t. LXVI, 203 (1983) 65-79; EVERGATES, Theodore - The Chancery Archives of the Counts of Champagne: Codicology and History of the Cartulary-Registers. Viator. 16 (1985) 159-180; SÁNCHEZ GONZÁLEZ, Antonio- Documentación de la Casa de Medinaceli: el Archivo General de los Duques de Segorbe y Cardona. Madrid. Ministerio de Cultura. 1990; AGUINAGALDE OLAIZOLA, Francisco de Borja - El Archivo de la Casa de Zabala. Cuadernos de Sección-Historia-Geografia-Eusko Ikaskuntza. 6 (1985) 199-311.

${ }^{25}$ BURKE, Peter - What is cultural history. Cambridge: Polity, 2008, 2a ed., p. 62 e seguintes. 
- não sendo a tal alheio de todo o seu papel de discurso fundador da Nação ${ }^{26}$ mas onde a arquivística sempre gozou de grande prestígio, tendo nas últimas décadas ultrapassado definitivamente o estatuto de disciplina auxiliar, graças à capacidade de actualização e discussão dos arquivistas franceses ${ }^{27}$. Como referem os editores: “( ... il nous est paru utile d'entreprendre, en contrepoint, une réflexion collective sur le statut épistémologique des archives et leur place dans la construction du savoir historique. Nous avons voulu construire ce dossier comme un dialogue entre les deux professions, les archivistes et les universitaires, et restaurer une distance critique à l'égard des enjeux politico-judiciaires afin de développer une réflexion scientifique autonome sur les archives. ${ }^{22}$. A revista reúne um significativo número de artigos de investigação e epistemologia arquivística, com questões de relevo.

Também de grande interesse se revestiu o encontro "Opening up the archives", realizado em 2006 no Radcliff Institute, da Universidade de Harvard. Organizado por Ann Blair e Jennifer Milligan, da Universidade de Harvard e do Marymount College (Nova Iorque), reuniu arquivistas e historiadores, constituindo-se como uma reunião de balanço do campo da "Social History of Archives". Teve como resultados a elaboração de um site temático, com esta última denominação ${ }^{29}$, Torna-se claro no texto introdutório da autoria das organizadoras e na conclusão final, por Peter

${ }^{26}$ GEARY, Patrick - O mito das nações. A invenção do nacionalismo. Lisboa: Gradiva, 2008.

${ }^{27}$ Ver o livro de identificação institucional FAVIER, Jean (dir.) - La pratique archivistique française. Paris: Archives Nationales, 1999; mais comemorativos: BÉCHU, Claire (coord.) - Les Archives nationales: des lieux pour l'histoire de France: bicentenaire d'une installation:1808-2008. Paris: Somogy Éd. d'Art ; Archives nationales, 2008 e BABELON, Jean-Pierre e outros - Les archives: mémoire de la France. Paris: Gallimard, 2008.

${ }^{28}$ ANHEIM, Étienne, PONCET, Olivier - Présentation. Revue de Synthèse. $5^{\mathrm{a}}$ série, 125 (2004) 1. O contraponto referido no texto é em relação aos "récents projects [qui] ont posé à nouveau la question de la placedes archives dans la société française contemporaine, par rapport aux pouvoirs publiques et aux utilisateurs, à commencer par les chercheurs professionnels", em particular a "Cité des archives", monumental obra em construção. Não se leia nas entrelinhas do texto uma subalternização da capacidade dos arquivistas para levarem a cabo esta reflexão sozinhos - a obra publicada e a actividade profissional, em França e nos organismos internacionais, dos arquivistas de uma escola com a École Nationale des Chartes fala por si - mas sim um apelo a um trabalho conjunto.

${ }^{29} \mathrm{http}$ ://isites.harvard.edu/icb/icb.do?keyword=k12884\&pageid=icb.page54165. A maior parte dos textos foi publicada em Archival Science. 7, 4 (2007). 
Burke $^{30}$ - que parte precisamente da New Cultural History, acima referida que o tema da história dos arquivos, não sendo novo, está numa etapa inicial de desenvolvimento, sob o signo da cooperação igualitária entre arquivistas e outros estudiosos das ciências sociais, incluindo historiadores, se bem que estes tenham sido os últimos a chegar ${ }^{31}$. Entre os diversos estudos de caso, destaca-se o artigo de Eric Ketelaar, parte de um inquérito mais vasto sobre o nascimento da concepção patrimonial dos arquivos ${ }^{32}$, e que teve como mais recente continuação a investigação da ocorrência daquela concepção precisamente nos arquivos de família ${ }^{33}$.

A perspectiva utilizada por esta corrente de estudos desloca o olhar dos conteúdos dos arquivos para a produção destes como objecto histórico: “(...) the definition of archives, and the authority that such a designation confers, has a history. While the archives as a collection has a history, the archives as an institution has a similarly (but not equivalent!) complex past. (...) These histories [os casos estudados] examine not just the content of the state collections, but reveal the workers of the producers, managers and users of these information storehouse. This focus on the production of archives rather than on mining the contents of archives is a crucial tool in understanding histories of power and the production of subjects and objects of knowledge. Indeed these institutional histories do much to suggest that the "archive" is as interesting to the historians for this infrastructure as for its contents." ${ }^{\text {. }}$. Para além do interesse do tema em si, há a vantagem adicional de um aprofundamento da auto-consciência do historiador contemporâneo, ao ajudar à desconstrução da objectividade da História positivista: se esta tem sido feita das mais diversas formas, é certo que o questionamento da objectividade das suas próprias bases, os grandes arquivos e edições documentais

${ }^{30}$ BLAIR, Ann e MILLIGAN, Jennifer - Introduction. Archival Science. 7, 4 (2007) 289-296 e BURKE, Peter - Commentary. Archival Science. 7, 4 (2007) 391-97.

${ }^{31}$ BLAIR, Ann e MILLIGAN, Jennifer - Introduction, cit., p. 289.

${ }^{32}$ KATELAAR, Eric - Muniments and monuments: the dawn of archives as cultural patrimony. Archival Science. 7, 4 (2007) 343-357.

${ }^{33}$ KETELAAR, Eric - The genealogical gaze: family identities and family archives in the Fourteenth to Seventeenth centuries. Libraries \& the cultural record. 4, 1 (2009) 9-28.

${ }^{34}$ BLAIR, Ann e MILLIGAN, Jennifer - Introduction, cit., p. 292. 
oitocentistas, é recente e merece a melhor atenção ${ }^{35}$. A História dos arquivos, em moldes sociológicos actualizados, é pois de um enorme interesse.

Em Portugal, dispomos de excelentes bases de trabalho, e mesmo de leituras complexas deste objecto histórico. Já em meados dos anos 90, ao redigir a sua tese de doutoramento, Fernanda Ribeiro referia a existência de um grande número de trabalhos sobre o tema, de variado estatuto, decerto, mas permitindo a síntese que depois empreende $u^{36}$. Os estudos desta autora e do grupo de investigação em que se insere, vieram depois possibilitar um salto qualitativo de monta na abordagem dos contextos históricos dos sistemas de informação arquivística em Portugal - destacando-se, entre outras muitas coisas, a demonstração da existência de uma periodização própria ao processo histórico da arquivística, que coincide, em larga parte, com as visões historiográficas mais recentes sobre a ruptura oitocentista ${ }^{37}$. De uma forma mais circunscrita, mas desbravando terrenos que requerem grande especialização, estudiosos da diplomática e das instituições têm realizado estudos, em especial sobre arquivos e práticas de arquivo no âmbito eclesiástico ${ }^{38}$.

${ }^{35}$ Para além dos estudos citados na nota 7, ver GEARY, Patrick - $O$ mito..., cit., que explica como edições documentais tão fundadoras da "objectividade histórica", como os Monumenta Germaniae Historica, e métodos tão "neutros" como a filologia, estavam, de facto, imbuídos de profundos projectos nacionalistas.

${ }^{36}$ RIBEIRO, Fernanda - O acesso..., cit., vol. 1, p. 56.

${ }^{37}$ RIBEIRO, Fernanda - $O$ acesso..., cit., vol. 1, p. 59 e seguintes SILVA, Armando Malheiro e outros - Arquivística..., cit., p. 70 e seguintes. Alguns artigos têm recentemente questionado dar à Revolução Francesa um papel de ruptura absoluta, salientando facturas antes estabelecidas e bloqueios que permaneceram, mas mantém-se a unanimidade sobre as novidades trazidas pelo século XVIII, que as revoluções liberais concretizaram de diversas formas. Como em todos os processos históricos há diferentes temporalidades, sendo que no caso das famílias parece dar-se uma delas, ver KETELAAR, Eric - The genealogical..., cit. e PANITCH, J. M.- Liberty, equality, posterity? Some archival lessons from the case of the French Revolution. American archivist. 59 (1996) 30-47.

${ }^{38}$ Sobre a arquivística medieval GOMES, Saul António - O "Inventário das Escrituras" do Convento de S. Francisco de Santarém de [1411]. Observações breves acerca da praxis arquivística medieval portuguesa. Revista de História da Sociedade e da Cultura. 3 (2003) [2004], 263-292; GOMES, Saul António - 'DONATIONES CVSTODIANTVR: DONATIONES SERVENTVR' Da memória e praxis arquivística do Mosteiro de Santa Maria de Alcobaça em tempos medievais. Humanitas. 57 (2005) 245-269. No âmbito da diplomática há diversas indicações sobre a produção documental, circulação e arquivagem em GOMES, Saúl António - «In limine conscriptionis». Documentos, chancelaria e cultura no Mosteiro de Santa Cruz de Coimbra (Séculos XII a XIV). Viseu: Palimage e Centro de História da Sociedade 


\section{A revalorização dos arquivos de família (sistemas de informação familiares)}

A investigação sobre a história dos arquivos de família é talvez um dos sectores mais estimulantes no âmbito da História de arquivos, em especial os de Antigo Regime. A partir da década de 90 do século XX assistiu-se a significativos marcos nesta tendência, que nos parece deverem-se à confluência de diversos desenvolvimentos disciplinares e sociais. Por um lado, um interesse da arquivística - num momento de debate e pesquisa identitária disciplinar muito intenso - por sistemas de arquivo não estatais (pois os estatais eram os que até então conferiam identidade de serviço público, sendo a relação com os arquivos privados mais problemática ${ }^{39}$ ). Por outro, o grande desenvolvimento a que se chegara, no âmbito da História Social sobre o Antigo Regime, nomeadamente no que toca à História da Família e das formas de ordenação societal ${ }^{40}$. Finalmente, pela valorização patrimonial e cultural de que começaram a ser alvo os arquivos de família em posse de privados. Não foi certamente por acaso que se assistiu, desde inícios daquela década e prolongando-se até hoje, à realização de reuniões alargadas sobre os arquivos de família, em Itália, França, Espanha e Portugal ${ }^{41}$, bem como a uma

e da Cultura da Universidade de Coimbra, 2007 e MORUJÃO, Maria do Rosário - A Sé de Coimbra: a instituição e a chancelaria (1080-1325). Coimbra, Faculdade de Letras, 2005.

${ }^{39}$ NOUGARET, Christine - Les archives privées, élements du patrimoine national? Des sequestres revolutionnaires aux entrées par voies extraordinaires: un siècle d'hésitation in Archivi e storia ..., cit., vol. 2, p. 737-750.

${ }^{40}$ Daqui resultando colóquios, ver INSABATO, Elisabeta - Le "nostre care scritture": la trasmissione delle carte di famiglia nei grandi casati toscani dal XV al XVIII secolo in LAMIONI, Claudio (ed.) - Istituzioni e società in Toscana nell'età moderna. Atti delle giornate di studio dedicate a Giuseppe Pansini. Roma: Ministero per Beni e le attività culturali; Ufficio Centrale per i beni archivistici, 1994, vol. II, p. 878-911; CASELLA, Laura, NAVARRINI, Roberto - Archivi nobiliari e domestici. Conservazione, metodologie di ordinamento e prospettive di ricerca storica. Udine: Forum, 2000, p. 7-10; VISCEGLIA, Maria Antonietta - Archivisti e storici di fronte agli archivi di famiglia. in CASELLA, Laura, NAVARRINI, Roberto (ed.) - Archivi nobiliari..., cit.,. p. 331-347; VILLANI, Pasquale - Gli archivi familiari e la ricerca in TASCINI, Irma Paola (dir) - Il futuro della memoria. Atti del convegno internazionale di studi sugli archivi di famiglie e di persone. Roma: Ministero per i beni culturali e ambientali, Ufficio centrale per i beni archivistici, 1997, vol. 1, p. 88-100.

${ }^{41}$ Referindo apenas os mais significativos, Itália: TASCINI, Irma Paola (dir) - Il futuro..., cit., (para a apreciação do até então realizado neste âmbito, sobretudo em Itália, mas também noutros países, ver a intervenção de LODOLINI, Elio - Archivi privati, archivi personali, archivi familiari, ieri ed oggi, vol. 1, p. 23-69) e CASELLA, Laura, NAVARRINI, 
explosão de trabalhos teóricos e práticos sobre o tema e, ainda, à realização de cadastros de vários tipos, desde os guias às bases de dados. Podemos distinguir três grandes campos no conjunto da produção bibliográfica. Por um lado, a preocupação com a valorização e salvaguarda patrimonial destes arquivos; depois, o estudo das formas de organização dos acervos; por fim, o contributo deste para a investigação histórica.

\subsection{A revalorização patrimonial dos arquivos de família}

Não sendo possível, no âmbito deste trabalho, uma revisão exaustiva do tema, salientemos os seus aspectos principais, mencionando alguns exemplos particularmente interessantes. É sabido que a dispersão patrimonial afecta muito este tipo de arquivos, que estão na posse de particulares e têm valor comercial. Tal como noutros âmbitos patrimoniais, tem-se oscilado entre uma tendência classificatória estatalista, mais ou menos intervencionista ${ }^{42}$, e uma política mais construtiva de informação e formação aos detentores de arquivos, que incentive a cooperação, para a qual têm sido definidas formas várias - que vão desde a regulamentação de custódias (doação, dação, depósito, inventariações com digitalizações, etc) à realização de acções

Roberto - Introduzione. Archivi nobiliari..., cit.; Espanha: (I) Simposium. Los archivos familiares en España: estado de la cuestión. Ed. Asociación para la defensa del patrimonio bibliográfico y documental de Cantabria. Santander, 1996 e SÁEZ, Carlos (ed.) - (II) Simposium archivos familiares. Valoracion y tasacion. Ed. Asociación para la defensa del patrimonio bibliográfico y documental de Cantabria. Santander, 2001, e Libros y documentos en la Alta Edad Media. Los libros de derecho. Los archivos familiares. Actas del VI congreso internacional de Historia de la Cultura Escrita (2001). Madrid, Calambur, 2002; Portugal: PEIXOTO, Pedro (ed.) - Arquivos de família e pessoais. Seminário. Vila Real: Associação Portuguesa de Bibliotecários, arquivistas e documentalistas, 1997; França - Les archives privées. Journées d'études des Archives départementales. Angers: 2005. Gazette des archives, 201 (2006) e FAVIER, René (ed.) - Archives familiales et noblesse provinciale. Hommage à Yves Soulingeas. Grenoble: Presses Universitaires de Grenoble, 2006.

${ }^{42}$ Discutindo os prós e contras da intervenção mais activa: PORRÀ, Roberto - Problemi della determinazione dei limiti alla consultabilità degli archivi privati dichiarati di notevole interesse storico in TASCINI, Irma Paola (dir) - Il futuro..., cit., vol. 1, p. 167-173 e MAORI, Cesare A. - La tutela giuridica degli archivi privati: il procedimento cautelare del sequestro giudiziario in TASCINI, Irma Paola (dir) - Il futuro..., cit., vol. 2, p. 753-757. 
de dinamização cultural e científica (exposições, colóquios) ${ }^{43}$. Uma última alternativa, posterior mas não menos interessante, é a do desenvolvimento de associações privadas de defesa e valorização deste património, com frequência em colaboração com as entidades públicas reguladoras do sector arquivístico e com os profissionais da área. É o caso da Association française de protection des archives privées, que não só operou desde a fundação em colaboração com a École des Chartes, através de um protocolo que enviava estagiários para realizar trabalhos de diagnóstico e inventariação, como tem, desde finais de 2008, assento no Conseil Supérieur des Archives ${ }^{44}$. Ainda neste âmbito, e seguindo o exemplo belga, tem sido invocada a figura da "sociedade de família" para evitar a dispersão dos arquivos ${ }^{45}$, e fala-se já do sector como uma possibilidade de trabalho para os arquivistas profissionais ${ }^{46}$. A França, de resto, tem dedicado especial atenção à temática legal e à delineação de grandes linhas de intervenção no sector, sendo disso expoente o recente manual publicado pelos Archives de France ${ }^{47}$, e a existência de uma base de dados dos arquivos de família em todos os arquivos centrais e departamentais franceses ${ }^{48}$. Em Espanha, a estrutura regional e a permanência da nobreza são dois factores que têm favorecido o florescimento de estudos e acções relativas à salvaguarda patrimonial

${ }^{43}$ LACOUSSE, Magali - Les archives privées au Centre Historique des Archives Nationales in Les archives au fils du temps. Paris: Fayard, 2002, p. 177-180 (entre outras coisas, formas de dinamização cultural de arquivos depositados no Arquivo Nacional); CRISTALDI, Gabriella de Longis - Vigilanza, tutela, valorizzazione in TASCINI, Irma Paola (dir) Il futuro ..., cit., vol. 1, p. 70-78; HERRERA MORILLAS, José Luis - El Palacio y el Archivo de Viana de Córdoba: un ejemplo de la desigual actitud ante la valoración y recuperación de los distintos patrimonios históricos in Libros y documentos ..., cit., p. 481-492.

${ }^{44}$ QUINSONAS-OUDINOT, Odon de - Introduction in Les archives au fils..., cit., p. 13-18. QUINSONAS-OUDINOT, Odon de-Du comportement des propriétaires d'archives privées et de leurs rapports avec les historiens in FAVIER, René (ed.) - Archives familiales..., cit., p. 69-74 e QUINSONAS-OUDINOT, Odon de - Aux côtés des services publics, l'action associative. Gazette des archives. 205-208 (2007) 26-31. Veja-se o site da associação: http:// www.archivesprivees.com/.

${ }^{45}$ DE MÉNÉVAL, Claude Napoléon - Contre le démembrement des fonds. La société de famille in Les archives au fils..., cit., p. 171-175.

${ }^{46}$ TOULHOUAT, Hélène - Un concept nouveau: l'archiviste au service des détenteurs d'archives privées. Gazette des archives. 205-208 (2007) 133-138.

${ }^{47}$ NOUGARET, Christine (et al.) - Les archives privées. Manuel pratique et juridique, Paris: Archives de France, 2008.

${ }^{48}$ BORA/Archives privées: http://daf.archivesdefrance.culture.gouv.fr/sdx/ap/index. xsp. 
dos arquivos de família. A título de exemplo, destaquemos o trabalho realizado desde inícios da década de 80 do século XX, pela Universidade de Valência ${ }^{49}$, acções bem recentes de salvaguarda e difusão cultural por circunscrições diversas, maiores ou menores, desde a Xunta de Galicia ${ }^{50}$ ao projecto local do Archivo Ducal de Hijar-Archivo Abierto ${ }^{51}$ - na esteira de uma tradição pioneira, quanto ao País Basco, liderada por Francisco Borja de Aguinagalde ${ }^{52}$ - e, claro, a constituição da Secção Nobreza do Arquivo Nacional, em Toledo ${ }^{53}$. A importância destes arquivos para a história local tem sublinhada por diversos autores ${ }^{54}$.

É justo destacar também a existência de uma forte dinâmica privada de salvaguarda e dinamização destes fundos, de que é exemplo maior a Fundação da Casa de Medinaceli (1978), detentora de um notabilíssimo acervo, descrito e aberto aos investigadores ${ }^{55}$; é posterior, em termos de

${ }^{49}$ PONS ALÓS, Vicente - Los archivos familiares: realidade y prospectiva desde la óptica del historiador de los archivos. in I Simposium. Los archivos..., cit., p. 44-78.

${ }^{50}$ MIGUÉS, Victor Manuel - Os arquivos privados e a nobreza: un apuntamento histórico-arquivístico: o caso galego a través do fondo do Marquesado de "San Martín" de Ombreiro. Santiago de Compostela: Xunta de Galicia 2002.

${ }^{51} \mathrm{O}$ fundo da Casa Ducal de Híjar está depositado no arquivo Provincial de Saragoça, e tem um site de suporte: http://www.archivoducaldehijar-archivoabierto.com/senhijar.html; ver ainda a recente publicação CASAUS BALLESTER, Maria José (coord.) - Jornadas sobre el señorio ducado de Hijar: sete siglos de história nobiliária. Hijár: [s. n.], 2007.

${ }^{52}$ Data de 1985 o seu primeiro artigo na temática, seguido de muitos outros, AGUINAGALDE OLAIZOLA, Francisco de Borja - El Archivo de la Casa de Zabala; desde 2000, está on-line este arquivo - www.snae.org/pdf/zavala.pdf. Do mesmo autor - "El Archivo de la Casa de Zavala. Método de organización e historia de la formación del Archivo. Inventario del Archivo de la Casa de Zavala. San Sebastián: [s. n.], 2000, vol. 1.

${ }^{53}$ A sua directora tem publicado vários artigos informativos: LAFUENTE URIÉN, Aránzazu - El Archivo de la Nobleza de Toledo: centro de conservación de fondos nobiliarios in Jornadas sobre el señorio..., cit., p. 43-86.

${ }^{54}$ DI SABANTONIO, B. - L'importanza degli archivi privati nello studio della storia locale. Rassegna degli archivi di Stato. XL (1980) 56-63 e TOLU, Rosalia Manno - Archivi privati in un contesto complesso in TASCINI, Irma Paola (dir) - Il futuro..., cit., vol. 1, p. 174-184.

${ }^{55}$ Veja-se o site http://www.fundacionmedinaceli.org. Entre vários trabalhos vejam-se de SÁNCHEZ GONZÁLEZ, Antonio - Documentación de la Casa de Medinaceli; El archivo condal de Ampurias: historia, organización e descripción de sus fundos. Madrid: [s. n.], 1993; El Archivo general de la Casa Ducal de Medinaceli: un modelo de aportacion de los Archivos Nobiliarios españoles a la ciencia archivistica complesso in TASCINI, Irma Paola (dir) Il futuro ..., cit.. vol. 1, p. 347-367 e de ROMERO TALLAFIGO, Manuel - Los documentos y el archivo como armas defensivas del linaje: el caso del Archivo Ducal de Medicinaceli in Jornadas sobre..., cit., p. 111-142. 
constituição institucional, a Fundação Casa de Medina Sidonia (1990), também detentora de um riquíssimo acervo, mas cujos fundos ainda não foram alvo de tratamento arquivístico e de investigação tão frequente como no caso anterior, embora a dinâmica recente aponte no mesmo sentido ${ }^{56}$.

Em Itália assiste-se a um panorama misto, em que a intervenção forte da Direzione Generale per gli archivi do Ministerio per i Beni e le attivitá culturali se fez sentir desde o início (à semelhança de outros sectores dos "arquivos privados"57: guia dos arquivos de família elaborado nos anos 80, tendo sido editado em 1991 o volume de Abrúzio/Ligúria ${ }^{58}$; colóquio internacional sobre o tema neste mesmo ano $^{59}$ ) e se complementou com a de universidades e fundações e associações eruditas locais ${ }^{60}$, cuja forte tradição de intervenção cultural as coloca numa posição privilegiada para alcançar a confiança dos proprietários de acervos ${ }^{61}$.

${ }^{56}$ Veja-se o site http://www.fcmedinasidonia.com; conhecemos o estudo de FRANCO SILVA, Alfonso - Los fondos documentales de los archivos de las Casas ducales de Medina Sidonia y Frias in Jornadas sobre..., cit., p. 97-110. Luisa Isabel Álvarez de Toledo, Duquesa de Medina Sidónia, escreveu também obras de carácter histórico, a partir do arquivo, bem como uma descrição deste arquivo, que não pudemos consultar (segundo informação do sítio, encontram-se esgotadas e serão republicadas).

${ }^{57}$ Como o dos arquivos eclesiásticos, Guida agli archivi diocesani d'Italia, de 1990 e, mais recentemente, os três volumes do Guida agli Archivi capitolari d'Italia. Roma: [s. n.], 2000-2006.

${ }^{58}$ PESIRI, Giovanni Pesiri e outros (ed.) - Archivi de famigli e di personne. I. Abruzo-Liguria. Materiali per una guida. Roma: Ufficio Centrale per i Beni Culturali, 1991.

${ }^{59}$ TASCINI, Irma Paola (dir) - Il futuro..., cit.. Aqui se encontram, também, vários artigos com informações sobre arquivos de família em diferentes regiões e arquivos estatais de Itália.

${ }^{60}$ SBRILLI, Milletta - L'archivio Salviati e il su deposito alla Scuola Normale Superiore: un esempio di valorizzazione in TASCINI, Irma Paola (dir) - Il futuro..., cit.., vol. 2, p. $539-544$

${ }^{61}$ Foi o caso do processo de depósito, reorganização e descrição dos arquivos genoveses ligados à família Palavicini, numa colaboração entre a Universidade e a Società Ligure di Storia Patria, ver BOLOGNA, Marco - L'archivio della famiglia Sauli: notizie sul riordinamento in corso. Atti della Società ligure di Storia patria. XXXV (1995) 213-225; BOLOGNA, Marco - L'Archivo Durazzo Pallavicini Giustiniani in TASCINI, Irma Paola (dir) - Il futuro ..., cit.., vol. 1, p. 311-332; os inventários propriamente ditos BOLOGNA, Marco (a cura di) - Gli Archivi Palavicini de Genova. I. Archivi propri. Inventario. Roma: [s. n.], 1994; BOLOGNA, Marco (ed.) - Gli Archivi Palavicini de Genova. II. Archivi aggregati. Genova, [s. n.], 1995; sobre todo o processo, PUNCUH, Dino - Gli archivi Pallavicini di Genova: una lunga «aventura». Atti della Società ligure di Storia patria, XXXV (1995), p. 241-251. Note-se que em Itália há legislação regional sobre os arquivos e o património, o que tem reflexos também neste sector, ver CAVALCOLI, Valeria - Per un 
Em Portugal tem sido mais tímida a acção e reflexão neste âmbito, embora se destaquem já marcos significativos, que urge consolidar. Nos anos 80, pelo que se pode julgar a partir dos dados disponíveis no volume VI do Guia de Fundos da Torre do Tombo ("Colecções, arquivos de pessoas singulares, de famílias, de empresas, de associações, de comissões e de congressos”), assistiu-se a um importante investimento patrimonial por parte do Estado (IPPC, Torre do Tombo), com a compra de numerosos fundos ou partes deles. Os depósitos tiveram então um papel modesto no conjunto das formas de aquisição (apenas cinco entre os mais recentes, um dos quais temporário - Casa Palmela) e mais ainda as doações (duas, a partir da década de 70). Entretanto, nos anos 90, desenvolvera-se no seio do extinto IPA, alguma reflexão técnica sobre os arquivos de família, se bem que dedicada sobretudo aos problemas de organização e descrição dos acervos. O "Grupo de trabalho sobre os arquivos de família”, também por esses anos criado na BAD, privilegiou os mesmos temas, mas encontra-se actualmente inactivo. Nesta conjuntura, Pedro Abreu Peixoto, dinamizador das acções referidas, publicou um pequeno estudo preconizando a extensão de uma "política de arquivos" a este sector, também no quadro de afirmação da identidade arquívistica que então se vivia (rede nacional de arquivos, políticas de arquivos, produção de instrumentos de descrição à escala nacional, discussão sobre a configuração do arquivo nacional, etc) ${ }^{62}$. Em 2007, a chamada de atenção sobre fundos que englobam os arquivos de família pertenceu a um outro grupo de trabalho da BAD, o dos arquivos municipais, cujo encontro anual de 2007 versou o tema Fundos Privados em Arquivos Municipais: Perspectivas e Projectos ${ }^{63}$. O facho mais continuado do cuidado patrimonial tem sido mantido pelo Congresso Casa Nobre, promovido pela Câmara Municipal de Arcos de Valdevez, e que conta com duas edições (2005 e 2008), estando publicadas as Actas da I e em vias de publicação as da $\mathrm{II}^{64)}$. Em termos de dinâmicas

esame comparativo delle normative regionali in materia di archivi privati in TASCINI, Irma Paola (dir) - Il futuro ..., cit.., vol. 1, p. 141-153.

62 PEIXOTO, Pedro Abreu-Aspectos essenciais para o desenvolvimento de uma política de arquivos. Os arquivos de família. Cadernos BAD. 1 (1994) 43-48.

${ }^{63}$ As actas não estão ainda disponíveis, mas podem encontrar-se informações em http://www.apbad.pt/Seccoes/S_ArqMunicipais/8EncontroArqMun.htm.

64 Casa Nobre-um património para o futuro: actas do $1^{\circ}$ congresso internacional. Arcos de Valdevez: Câmara Municipal dos Arcos de Valdevez, 2007. É de referir que estes 
privadas, exemplos pioneiros como o das Fundações da Casa de Mateus e da Casa de Fronteira, merecem o maior destaque, de modo a proporcionar alargamento e continuidade ${ }^{65}$. Quanto às autoridades públicas centrais, os dados fornecidos pelo Boletim da Dgarq (ex Boletim do IAN/TT) permitemnos supôr que se assiste a um lento inverter da situação, com o aumento dos depósitos - o Arquivo dos Viscondes de VNC (2000) e o da Família Saldanha Albuquerque e Castro Ribafria (Penamacor) Lima e Melo Falcão Trigoso (2008) - e doações (Arquivo da Família Gama Lobo Salema) ${ }^{66}$. Saliente-se que os três acervos são amplos conjuntos documentais, tanto em número de documentos como de amplitude temporal. Estamos, no entanto, ainda longe do panorama dos restantes países que temos vindo a analisar, em que se está já numa fase muito proactiva, com publicação das descrições, dinamização cultural, colaboração com as universidades, promoção de debates, elaboração de documentos legais e de manualística, como acima referido.

\subsection{Revalorização da história dos sistemas de informação familiares como forma de propor organizações arquivísticas adequadas}

O estudo da forma como os arquivos de família surgiram e foram sendo mantidos tem neste momento algumas linhas principais. Destacaríamos,

congressos se inserem numa dinâmica mais antiga, a do "Projecto Casas Armoriadas do Concelho dos Arcos de Valdevez", com focalização num objecto diverso, mas que tem permitido o contacto com o meio afim dos arquivos de família (que conta já com cinco volumes de inventário editados, de 1989 a 2004).

${ }^{65}$ Casa de Mateus. Catálogo do Arquivo. Vila Real: Fundação da Casa de Mateus, 2005. Veja-se o site http://www.casademateus.com/home.htm. O actual Marquês de Fronteira vendeu à Torre do Tombo, em 1975, o arquivo que então detinha na sua posse. No entanto, após a criação da Fundação das Casas de Fronteira e Alorna, tem reunido nesta, por compra, documentação que se encontrava dispersa, ver Guia Geral dos Fundos da Torre do Tombo, vol. VI, p. 197, e informação constante no sítio da Fundação, em "Família/arquivos". A Fundação tem uma extensa actividade cultural, ver http://www.fronteira-alorna.pt/index. htm.

${ }^{66}$ SARAIVA, Teresa - O arquivo dos Viscondes de Vila Nova de Cerveira. Boletim da Dgarq. 4 (Janeiro-Março 2008) 5; RAMOS, Maria Fátima Dentinho do Ó - Depósito de bens arquivísticos. Boletim da Dgarq. 4 (Janeiro-Março 2008) p. 9 [Arquivo da Família Saldanha Albuquerque e Castro Ribafria (Penamacor) Lima e Melo Falcão Trigoso] e SARAIVA, Teresa $-\mathrm{O}$ arquivo da família Gama Lobo Salema. Boletim da Dgarq. 5 (Abril-Junho 2008) 4. 
em primeiro lugar, a busca e análise de testemunhos mais antigos deste movimento, que para a Alta Idade Média se tem centrado na questão da produção de cartulários pelas administrações eclesiásticas e a sua influência nos acervos documentais da nobreza leiga a elas associada ${ }^{67}$. Quanto às centúrias do estabelecimento das monarquias feudais, embora seja central o tema do desenvolvimento da prova escrita como essencial ao reforço da administração régia - onde é imprescindível sublinhar a influência dos estudos pioneiros de Michael Clanchy ${ }^{68}$ - vão surgindo estudos que destacam a proximidade epocal e metodológica da organização dos arquivos senhoriais, que são melhor conhecidos sobretudo do século XIV em diante ${ }^{69}$. A consciência genealógica que por esta altura é uma tendência firme na

${ }^{67}$ KOSTO, Adam Kosto; WINROTH, Anders (ed.) - Charters, chartularies and archives. The preservation and transformation of documents in the medieval west. Proceedings of a colloquium of the Cons international de Diplomatique, Princeton and New York, 16-18 September 1999. Toronto: Pontifical Institute of Mediaeval Studies, 2002; DECLERCQ, Georges - Originals and chartularies. The organization of archival memory (ninth-eleventh centuries) in HEIDECKER, Karl (ed.) - Charters and the use of written word in medieval society. Turnhout: Brepols, 2000, p. 147-170; HECHT, Alexander - Between memoria, historiography and pragmatic literacy: the Liber Delegacionum of Reichersberg in HEIDECKER, Karl (ed.) - Charters ..., cit., p. 205-211 e GASPARRI, Stefano; LA ROCCA, Cristina (ed.) - Carte di famiglia: strategie, rappresentazione e memoria del gruppo familiare di Totone di Campione (721-877). Roma: Viella, 2005.

${ }^{68}$ CLANCHY, M.T. - From Memory to Written Record: England, 1066-1307, 1979; Archives and Memory in the Middle Ages. Archivaria. 11 (1981) 115-125; e a 2a edição revista de From memory. Oxford: Blackwell, 1993.

${ }^{69}$ GUIARD, Patricia - La gestion de l'écrit dans une famille de serviteurs du roi. Le cartulaire et le chartrier des Mignons. Bibliothèque de l'École des Chartes. 157 (1999) 523-563; VON KAENEL, Vivianne - Histoire patrimoniale et mémoire familiale: l'inventaire des archives de la famille Bouvier:1445. Lausanne: Univ Lausanne, 2003; RÜCK, Peter L' ordinamento degli archivi ducali di Savoia sotto Amedeo VIII: (1398-1451). Roma, 1977 (separata de Quaderni della Rassegna degli Archivi di Stato, 48); CECCHI ASTE, Elena (ed.) - Il carteggio di Gaeta: nell'archivio del mercante pratese Francesco di Marco Datini 1387-1405. Gaeta: Edizioni del comune di Gaeta, 1997; RICHARD, J. - Les archives et les archivistes des ducs de Bourgogne dans le resort de la Chambre des Comptes de Dijon. Bibliothèque de l'Ecole de Chartres, CV (1944) 123-169; EVERGATES, Theodore - The Chancery Archives of the Counts of Champagne: Codicology and History of the Cartulary-Registers. Viator. 16 (1985) 159-180; CONDE Y DELGADO DE MOLINA, Rafael - Archivos y archiveros en la Edad Media peninsular. Historia de los archivos y de la archivistica en España, p. 13-28; NAVARRO BONILLA, Diego - El proceso de inventário de escrituras: fuente documental para una história social dela cultura escrita en Aragón in CLARAMUNT, S. (coord.) - El món urbà la Corona d'Aragó del 1137 als decrets de nova planta. XVII Congrès d'Historia de la Corona d'Aragó. Actas. Barcelona: Universidad Barcelona, 2003, vol. II, p. 807-816. 
Europa ocidental ${ }^{70}$ - e revestindo, no Sul, formas tão acabadas com os morgadios e fideicomissos - influenciará os esforços para a reorganização dos arquivos, embora cada caso tenha de ser estudado a fundo, para evitar o que Joseph Morsel relata quanto aos fundos da nobreza alemã tardo-medieval ${ }^{71}$. Conhecem-se já bem algumas tendências gerais, como a relação directa entre formas sucessórias mais estruturadas e a conservação dos documentos, muitas vezes objecto de uma verdadeira gestão familiar ${ }^{72}$; ou a influência que sobre estes arquivos - em especial os maiores - exerceram os arquivos régios no que toca à abertura ao público (que foi a par com uma abertura menos voluntária, a provocada pela exigência de prova quanto ao estatuto e posses nobres, à cadência da centralização monárquica $)^{73}$. Nos séculos subsequentes, as principais tendências evolutivas deste tipo de arquivo são a complexificação administrativa e - em especial influente nas reorganizações - o triunfo da concepção patrimonial e da consciência histórico-genealógica, que trará modificações de fundo, nomeadamente a constituição de "secções históricas", as primeiras grandes desorganizadoras dos sistemas anteriores ${ }^{74}$. No final do Antigo Regime, seguindo tendências

${ }^{70}$ KETELAAR, Eric - The genealogical gaze..., cit.,; WOOLF, Daniel - The Social Circulation of the Past. English Historical Culture 1500-1730. Oxford: Oxford University Press, 2003.

${ }^{71}$ MORSEL, Joseph - Le médiéviste, le lignage et l'effet de réel. La construction du Geschlecht par l'archive en Haute-Allemagne. Révue de Synthèse. 125 (2004) 83-110. Reflecte sobre este mesmo aspecto, numa investigação a partir de fundos familiares, LEMONDE, Anne - Les Allemand et le Dauphin (XIIIe-XVe siècle): du lignage médiéval au lignage moderne, réflexion sur les recompositions de la noblesse à la fin du Moyen Âge in FAVIER, René (ed.) - Archives familiales..., cit., p. 127-148.

${ }^{72}$ INSABATO, Elisabeta - Le "nostre care scritture"..., cit., p. 885-887. RAINES, Dorit - L'arte di ben informarsi. Carriera politica e pratiche documentarie nell'archivio familiare di patrizi veneziani: i Molin di San Pantalon in CASELLA, Laura, NAVARRINI, Roberto (ed.) - Archivi nobiliari..., cit., p. 187-210.

${ }^{73}$ RODRÍGUEZ DE DIEGO, J.L. \& J.T. - Un archivo no solo para el Rey. Significado social del proyecto simanquino en el siglo XVI in MARTÍNEZ MILLÁN, J. (ed.) - Felipe II (1527-1598). Europa y la Monarquía Católica, vol. IV, 463-475. Madrid: Europa, 1998; COULOMB, Clarisse - La publicité des archives de la noblesse sous l'Ancien Régime: l'exemple du Dauphiné, XVIIe-XVIIIe. siècle in FAVIER, René (ed.) - Archives familiales..., cit., p. 89-101

${ }^{74}$ INSABATO, Elisabeta - Le "nostre care scritture"..., cit., p. 878-911; INSABATO, Elisabeta - Un momento fondamentale nell'organizzazione degli archivi di famiglia in Italia: il Settecento in TASCINI, Irma Paola (dir) - Il futuro..., cit... vol. 1, p. 289-310; AGUINAGALDE OLAIZOLA, Francisco de Borja - Erudición y organización de archivos 
mais gerais a todos os sistemas de informação e às concepções de organização da sociedade, as classificações de ordem temática e racionalista fazem a sua entrada, provocando, por vezes, verdadeiras revoluções na organização dos materiais ${ }^{75}$.

Não há unanimidade quanto ao quadro de classificação. Em Espanha, os arquivistas da Sección Nobleza do Archivo Histórico Nacional optaram pela elaboração e aplicação generalizada de um quadro de classificação temático-funcional, com alguma espessura histórica, mas reconhecidamente uma solução de compromisso em relação aos resultantes de investigações aprofundadas $^{76}$ (na linha do já proposto por Olga Gallego Domínguez para os arquivos familiares em geral, no início dos anos $90^{77}$, e dos trabalhos de Borja Aguinagalde ${ }^{78}$ ). Continuam a existir em Espanha organizações

privados en la monarquía absoluta: de la función común a la configuración de una profesión específica in GIMENO BLAY, Francisco M. (ed.) - Erudición y Discurso Histórico: las instituciones europeas (s. XVIII-XIX). Valencia: Universitat, 1993, p. 129-156.

${ }^{75}$ ANGELINI, Massimo - La cultura genealogica in area ligure nel XVIII secolo: introduzione ai repertori delle famiglie. Atti della Società ligure di storia patria. Nuova serie, XXXV/CIX (1995) 189-212; VALDÈS, Marina - Ordinamenti ottocenteschi negli archivi feudali sardi: gli archivi Amat di San Filippo e Amat di Settecento in TASCINI, Irma Paola (dir) - Il futuro..., cit.., vol. 2, p. 816-827; PAPAGNA, Elena Archivi di familia nel Mezzogiorno d'Italia. Il caso dei Caracciolo di Brienza-Martina in CASELLA, Laura, NAVARRINI, Roberto (ed.) - Archivi nobiliari e domestici, p. 276-298; RIVA, Elena - Tra Como e Milano - Storie e memorie familiari nella seconda metà del Settecento Pantalon in CASELLA, Laura, NAVARRINI, Roberto (ed.) - Archivi nobiliari..., cit., p. 299-330 e SILVA, Armando Malheiro e outros - Arquivistica..., cit., p. 95 e seguintes.

${ }^{76}$ GARCÍA ASER, Rosario; Aránzazu LAFUENTE URIEN - Archivos Nobiliarios, cuadro de clasificación. Sección Nobleza del Archivo Histórico Nacional. Madrid: Ministerio de Educación, Cultura y Deporte, 2000; LAFUENTE URIÉN, Aránzazu - Los archivos familiares: La Sección Nobleza del Archivo Histórico Nacional. Tratamiento archivístico y fuentes documentales. in La investigación y las fuentes documentales de los archivos. Iy II Jornadas sobre investigación en archivos, Guadalajara: ANABAD Castilla-La Mancha, Asociación de Amigos del Archivo Histórico Provincial, 1996, p. 975-998; discutindo os prós e contras do quadro de classificação-tipo, MAS GONZÁLEZ, Carlos - Cuadros de clasificación de archivos nobiliarios. La iniciativa de la Sección Nobleza del Archivo Histórico Nacional in Libros y documentos..., cit., p. 493-500. Ver ainda as apreciações globais de BLASCO MARTÍNEZ, Rosa Maria - Los archivos familiares. Planteamiento general y custiones para el debate in Libros y documentos ..., cit.,. p. 391-403.

${ }^{77}$ GALLEGO DOMÍNGUEZ, Olga - Manual de archivos familiares. Madrid: ANABAD, 1993.

${ }^{78}$ AGUINAGALDE OLAIZOLA, Francisco de Borja - Archivos de Familia: Materiales Para Un Manual: Master de Archivística Vitoria-Gasteiz]. Irargi: Centro de Patrimonio 
diversas, feitas a partir de maior investigação ${ }^{79}$, incluindo as que se baseiam na sequência geracional ${ }^{80}$; a permanência dos documentos nos seus sistemas produtores, alguns dos quais muito elaborados e dotados de arquivistas profissionais, a isso tem ajudado, sendo o mais notório o da Casa Ducal de Medinaceli ${ }^{81}$.

O mesmo poderíamos dizer de Itália ${ }^{82}$, enquanto em França a força da tradição dos Archives Nationales, já secular, tem contribuído para uma uniformização acentuada - tanto mais que há muitos fundos depositados em arquivos públicos ${ }^{83}$.

Para além do estudos das formas de organização antigas e das classificações a seguir, começam a surgir investigações sobre aspectos a que poderíamos chamar mais histórico-sociológicos, no âmbito dos “usos sociais

Documental de Euskadi, 1991; Los archivos de familia. Definición, estructura, organización. Nuevos extractos de la Real Sociedad Bascongada de los Amigos del País. Comisión de Guipúzcoa. 5 (1992) p. 9-37.

${ }^{79}$ Cfr. os trabalhos de Antonio Sánchez González citados na nota 55 e ainda, entre outros, AGUINAGALDE OLAIZOLA, Francisco de Borja - El Archivo de la Casa de Zavala. Método de organización e historia de la formación del Archivo in Inventario del Archivo de la Casa de Zavala. Volumen I. Introducción. San Sebastián: [s.n.], 2000, p. 17-146 (disponível em www.snae.org/pdf/zavala.pdf). CANELLAS ANOZ, Beatriz -Tratamiento archivistico de los fondos patrimoniales del Archivo de la Corona de Aragón, in Il futuro della memoria. vol. 1, p. 230-241; FLORES VARELA, Carlos - Sobre la organización de la documentación señorial. Boletín ANABAD. XLVII, 1 (Janeiro 1997) 29-55; FLORES VARELA, Carlos - El estado señorial de Gálvez: organización institucional y documental in La investigación y las fuentes..., cit., vol. 2, pp. 999-1013.

${ }^{80}$ GONZÁLEZ NICOLÁS, Elena; LAVÍN GARCÍA, María Jesús - La organización del archivo de San Roman de Escalante in Libros y documentos..., cit., p. 417-428.

${ }^{81}$ Ver supra nota 55.

${ }^{82}$ É o caso da reflexão teórica feita a partir da reorganização dos arquivos Palavicini por BOLOGNA, Marco - Per un modello generale degli archivi di famiglia. Atti della Società ligure di Storia patria. XXXVI, 2 (1996) 553-588. A defesa da aplicação do método histórico em arquivos de família depositados em arquivos públicos é feita por CORBELLINI, Roberta - Gli archivi privati dell'Archivio di Stato di Udine, con una reflessione sul metodo storico. in CASELLA, Laura, NAVARRINI, Roberto (ed.) Archivi nobiliari..., cit.,. p. 135-150; ver ainda a interessante proposta de BIZZOCHI, Roberto - Un archivio primogeniturale: Bracci Cambini, Pisa, secoli XVII-XIX in CASELLA, Laura, NAVARRINI, Roberto (ed.) - Archivi nobiliari..., cit... p. 241-253.

${ }^{83}$ Para além da base de dados BORA, citada na nota 48, ver D'HUART, Suzanne; DE TOURTIER-BONAZZI, Chantal ; SIBILLE, Claire (rev. e ed.) e NOUGARET, Christine (dir.) - Etat sommaire des fonds d'archives privées: séries AP (1 à 629 AP) et AB XIX. Paris: Centre historique des Archives nationales, 2004; e o colóquio editado na Gazette des Archives de 2006 (ver nota 41). 
dos sistemas de informação arquivísticos": usos escrita, do arquivo, reforço da coesão familiar ${ }^{84}$.

Em Portugal estivemos longe de uma dinâmica de investigação de história arquivística como a que testemunham os trabalhos anteriores. No entanto, deve referir-se a existência de uma reflexão sobre a organização dos arquivos familiares de Antigo Regime que, apesar de escassa, tem evoluído num sentido muito positivo, se bem que a necessitar de maior difusão e aproveitamento. Como ponto de partida, podemos apontar o início da década de 90 quando, a par de outros quadros de classificação temático-funcionais elaborados no seio do IPA, surgiu o já referido trabalho de Pedro Abreu Peixoto ${ }^{85}$. Não se torna necessário historiar de forma pormenorizada o desenvolvimento deste campo, uma vez que tal já foi feito por Armando Malheiro da Silva ${ }^{86}$. Cabe dizer que se verificou um abrandamento da dinâmica inicial por parte dos arquivistas que a tinham lançado (Pedro Abreu Peixoto, Paulo Mesquita Guimarães), para surgir de forma mais isolada, mas teoricamente mais consolidada, em torno de um projecto de reorganização de um grande arquivo de família, o da Fundação Casa de Mateus, a partir de $2001^{87}$.

${ }^{84}$ A título de exemplo CASAUS BALLESTER, Ma José, La Casa De Híjar (Teruel) y el uso de algunos archivos. Boletín de la Sociedad Española de Ciencias y Técnicas historiográficas. 2 (2006) 103-222; GUIARD, Patricia - La gestion de l'écrit dans une famille de serviteurs du roi.., cit.; VON KAENEL, Vivianne, Histoire patrimoniale et mémoire familiale.., cit.; HEAD, Randolph - Knowing like a state: the transformation of political knowledge in Swiss archive inventories, 1470-1770. Journal of Modern History. 75/4 (2003) 745-782; IRANZO MUÑIO, María Teresa - El archivo de la Casa Ducal de Híjar. Memoria, poder y relaciones de parentesco y España, siglos XV-XX. Jornadas sobre el señorio ducado de Hijar, p. 187-210; NAVARRO BONILLA, Diego - La imagen del archivo: representación y funciones en España (siglos XVI y XVII). Somonte: Cenero, 2003; ROMERO TALLAFIGO, Manuel - Los documentos y el archivo como armas defensivas del linaje: el caso del Archivo Ducal de Medicinaceli, in CASAUS BALLESTER, Ma José (coord.) - Jornadas sobre el señorio ducado de Hijar: sete siglos de história nobiliária. Hijar: [s.n.], 2007, p. 111-142.

${ }^{85}$ Pedro Abreu Peixoto, Arquivos de família. Orientações para a organização e descrição dos fundos dos arquivos de família. Lisboa: IPA, 1991.

${ }^{86}$ SILVA, Armando Malheiro da - Arquivos familiares e pessoais, cit.

${ }^{87}$ SILVA, Armando Malheiro da - A Casa de Mateus e a memória: o acesso sistémico a séculos de documentos na era da informação in Casa de Mateus. Catálogo do arquivo..., cit., p. 13-31. 
A par destes estudos, são cada vez mais frequentes os trabalhos de reorganização de acervos familiares. Deles resultam por vezes ricas experiências, em que se misturam os aspectos de História das estruturas de arquivo e as propostas de organização dos materiais. Por vezes, aplicam-se quadros de classificação de escassa espessura histórica, mas a investigação genealógica, contextual e sobre as práticas de arquivagem de muitos deles, traz contributos válidos à elaboração de propostas de organização mais complexas e fiéis à realidade dos sistemas de arquivo antigos ${ }^{88}$.

\subsection{Sistemas de informação familiares e investigação histórica}

A investigação histórica sobre as Épocas Medieval e Moderna tem sido enriquecida pela revalorização dos arquivos de família de dois modos diversos. Em primeiro lugar, pelos contributos informativos que traz, nomeadamente a biografias, prosopografias, estudos sobre as diversas formas de organização do parentesco ${ }^{89}$. Depois - e isto reputamos essencial - o uso da informação produzida pelas próprias famílias permite estudar a forma com este corpo social se auto-organizava, auto-identificava, auto-reproduzia e auto-sustentava. Quanto ao estudo dos seus arquivos, em particular, verifica-se a mesma riqueza de conteúdos (quantitativos e qualitativos, destacando-se quanto a este as tipologias documentais raras ou inexistentes noutros fundos) mas, talvez ainda mais importante, a possibilidade de medir o papel da gestão documental na estruturação e manutenção do corpo linhagístico. No cômputo global, pode dizer-se, em certos aspectos, que o uso desta documentação permite a entrada na História de actores até agora mal conhecidos, pouco conhecidos ou mesmo ignorados e, no seu conjunto, possibilita o questionamento de versões do processo histórico construídas, sobretudo ou apenas, a partir dos acervos dos corpos

${ }^{88}$ Ver o levantamento de RIBEIRO, Fernanda-O acesso ..., cit.., a completar com os de SILVA, Armando Malheiro da - Arquivos familiares..., cit. e Arquivos de família..., cit..

${ }^{89}$ Foi o caso do manancial de dados que o acesso ao Arquivo dos Viscondes de Vila Nova de Cerveira, no ANTT, trouxe ao trabalho de investigação de FARELO, Mário Sérgio - A oligarquia camarária de Lisboa (1325-1433). Lisboa: [s. n.] 2008 (dissertação de doutoramento em História Medieval apresentada à Faculdade de Letras da Universidade de Lisboa). 
sociais mais "administralizados" e/ou mais representados nos arquivos do Estado nação $0^{90}$.

Em relação ao caso português, seria antes de mais importante fomentar a reflexão sobre o tema e a confluência de esforços. Há uma situação algo paradoxal, que se traduz pela existência de um significativo número de estudos de grande qualidade sobre a organização familiar e a utilização de capitais simbólicos por parte da nobreza, em especial, mas sem que tal tenha levado ao questionamento mais profundo do uso/desuso de fontes próprias do corpo linhagístico nobiliárquico ${ }^{91}$. Assim, o prosseguimento dos estudos e a ausência de determinados tópicos tem a ver, em primeiro lugar, com a inexistência quase total dos arquivos de família no elenco de fundos disponíveis nos arquivos públicos, seja ela real, ou apenas criada por descrições insuficientes ou inadequadas, ou ainda por falta de difusão cultural dos serviços de arquivo. Em segundo lugar, com a escassez de arquivos privados abertos a consulta pública (pelo menos, aos investigadores credenciados). Há ainda uma dependência grande do paradigma oitocentista de "arquivo nacional" quando se pensa na constituição de corpus documentais para as investigações históricas de períodos a ele anteriores e alheios, em

${ }^{90}$ FIGEAC, Michel - À la recherche de la noblesse dans les archives privées de l'Aquitaine: un second ordre retrouvé? in FAVIER, René (ed.) - Archives familiales..., cit., p. 181-196; MENSION-RIGAUD, Éric - L'historien et les archives privées in Les archives au fils du temps..., cit.,, p. 21-26; LAFUENTE URIÉN, Aránzazu - Fuentes para los estudios genealógicos y familiares en los archivos nobiliarios. Revista Hispania. LX, 206, (2000) 977-1000; VISCEGLIA, Maria Antonietta - Archivisti e storici di fronte agli archivi di famiglia..., cit.; NOUGARET, Christine - L'intérêt des archives privées pour l'Histoire. Gazette des archives. 201 (2006) 19-25; RUITENBERG, Geertruida Maria Wilhelmina - Access to private archives as historical sources in the Netherlands, in TASCINI, Irma Paola (dir) - Il futuro..., cit.., vol. 1, p. 193-201; LITZEN, VEIKKO The new challenges of the Finnish family historians in TASCINI, Irma Paola (dir) - Il futuro..., cit.., vol. 1, p. 202-209. Da parte dos historiadores, uma renovação da monografia familiar tem incluído o questionamento das fontes, ver AURELL, Martin (ed.) - Le médiéviste et la monographie familiale: sources, méthodes et problèmatiques. Turnhout: Brepols, 2004.

${ }^{91}$ Seja-nos permitido remeter para estudos onde abordámos o assunto ROSA, Maria de Lurdes - Em torno de Álvaro Vaz, cavaleiro de Santiago (m. 1513): um estudo das formas de estruturação das eleites sociais "intermédias" in FERNANDES, Isabel C. (ed.) - As Ordens militares e as Ordens de cavalaria entre o Ocidente e o Oriente. Actas do V Encontro sobre Ordens militares. Palmela: GEOS-Município de Palmela, 2009, p. 187-245 e Sociabilidades e espiritualidades na Idade Média: a historiografia portuguesa sobre os comportamentos religiosos dos leigos medievais in Actas das Jornadas Lusitania Sacra, Universidade Católica Portuguesa (no prelo). 
termos de produção, circulação e conservação da informação. A tentativa de colmatar estas falhas tem-se feito através do recurso legítimo - e muitas vezes extremamente trabalhoso - a fundos documentais com os quais o corpo familiar se cruzava, e nos quais deixou vestígios. Porém, o carácter de esfera de intersecção do que daqui resulta raramente é teorizado como tal. Nestes fundos, que são maioritariamente os da Coroa e da Igreja (em especial as instituições religiosas), encontram-se sinais da produção de informação do corpo linhagístico que são, por vezes, quase absolutos (as cópias de documentos - mas não nos esqueçamos que a simples obrigatoriedade das cópias já testemunha de uma fase de ingerência na produção de informação familiar), mas, as mais das vezes, apenas relativos, porque filtrados pelo tipo de relação que os dois produtores de informação estabeleciam. A investigação construída a partir do método prosopográfico - que consiste em reunir o maior número de informações possíveis sobre um personagem, subalternizando a esta categoria uma explicitação sobre a proveniência das informações - deixa de lado aqueles problemas. A solução não será tanto, ou apenas, aumentar o número de fundos vistos, numa diligência explicativa que afinal seria sobretudo substancialmente cumulativa. É preciso antes de mais reconstruir o universo de produção informacional que rodeava o personagem (não basta a sua versão mais simples, a explicitação dos fundos a que se recorreu), caracterizar o tipo de informação que cada uma das instâncias produziria, e depois mapear a sua existência e ausência. Assim, o que subsiste teria bem definidos os seus limites, em termos de possibilidade de explicação histórica. Uma vantagem colateral, embora de monta, seria ainda o facto de que as sucessivas eliminações e arrumações arquivísticas - a começar pelas operadas pelos próprios produtores da documentação terem assim menos hipótese de serem interpretadas de formas erróneas, que vão desde o clássico "em Portugal não há fontes para isto pela sua especificidade histórica", até aos objectos históricos criados a partir de determinada configuração arquivística epocal e depois retroprojectados (em boa parte, o caso da estrutura linhagística $)^{92}$.

${ }^{92}$ MORSEL, Joseph - Le médiéviste..., cit.. 


\section{O Arquivo dos Viscondes de Vila Nova de Cerveira}

O Arquivo dos Viscondes de Vila Nova de Cerveira está depositado no Arquivo Nacional da Torre do Tombo desde finais de 2000, através de um contrato de depósito com representantes da família proprietária ${ }^{93}$. Segundos os termos deste, o Arquivo Nacional deveria "proceder ao tratamento técnico da documentação entregue" ${ }^{94}$. Em termos de organização e descrição documental, o trabalho está disponível desde inícios de 2009, na base de dados geral da DGARQ (Digitarq), na qual se pode consultar até ao nível "documento simples". A versatilidade informática permite um uso multiforme da descrição, o que é uma enorme vantagem. É possível realizar trabalhos de diversa natureza sobre a base de dados, nomeadamente o da pesquisa de dados simples.

$\mathrm{Na}$ esteira das ideias que temos vindo a expôr, porém, é preciso ir um pouco mais longe na apreciação da descrição, uma vez que o "IDD" proposto não é sequer um simples catálogo cronológico (sendo que mesmo estes impõem uma determinada estruturação da documentação que não é simples). Os documentos, simples e compostos, estão directamente dependentes de "secções". Não existem séries, portanto, o que permitiria reconhecer melhor as formas de produção documental e, ainda, trabalhar melhor com grandes grupos homogéneos de informação. Num segundo momento, nas secções propostas, verifica-se uma combinação entre a organização original e atribuída. A primeira a partir de três instrumentos de descrição existente no arquivo, e que surge como algo entre o orgânico e o topográfico. A segunda, a que atribuiríamos um carácter funcional/orgânico (com cinco secções, as primeiras três serão de natureza funcional: "organização e constituição do arquivo", "administração da casa", "contencioso"; as restantes, orgânicas (?) "Marqueses de Ponte de Lima" e "Deado de Évora". Por fim, uma colecção ("Colecção de documentos"). A organização original é atribuída a partir de três documentos existentes no acervo documental, sendo que dois são de

${ }^{93}$ SARAIVA, Teresa - O arquivo dos Viscondes de Vila Nova de Cerveira; e campo "modalidades de aquisição" na descrição ao nível "fundo" na base de dados Digitarq, no site da DGARQ (http://digitarq.dgarq.gov.pt/).

${ }^{94}$ Além de um conjunto de tarefas ligadas à reprodução e comunicação: cfr. SARAIVA, Teresa - $\mathrm{O}$ arquivo dos Viscondes de Vila Nova de Cerveira, cit. 
facto algo no âmbito de "inventários", e o terceiro é um livro de registo de rendimentos ${ }^{95}$.

Não é nossa intenção proceder a uma crítica aprofundada deste labor, que tem a grande virtude de disponibilizar os documentos. Se referimos a estrutura da descrição foi para ressalvar que a documentação é proposta sob certa forma, caso passemos para além da utilização simples da informação. Essa forma teria tudo a ganhar se fosse feita de acordo com os métodos da investigação histórica em arquivos, recorrendo aos muitos exemplos disponíveis. A disponibilização da documentação pelo ANTT vem, porém, agora possibilitar este trabalho, que seria difícil de realizar em âmbito não científico. Apontemos algumas pistas para tal.

Em primeiro lugar, é necessária uma definição clara do tipo de arquivo que está presente. Como é justamente indicado ${ }^{96}$, a documentação passou por grandes vicissitudes, tendo sido reunida pela família nos anos anteriores ao depósito. A título de exemplo, uma claríssima e muito prejudicial ausência é a de livros de registo: em termos comparativos, há muitíssimo mais documentos soltos do que livros. Depois, é um conjunto documental complexo, pertencendo a uma casa titular (e não a uma mais simples "família"). Por fim, a casa titular em questão, embora tenha sido das mais estáveis e tenha feito parte do grupo dos «puritanos», a que Nuno Monteiro atribui alguma influência e supremacia ${ }^{97}$, foi antes de mais um sistema agregador de alianças e patrimónios, que parece ter sabido utilizar com grande mestria os mecanismos de resolução de problemas sucessórios de diferente índole (perdas de varonia naturais ou acidentais, problemas sucessórios de natureza política durante a Restauração, perseguição pelo Marquês de Pombal, etc). Funcionando assim, a relação com a informação produzida era fundamental, nas suas vertentes da conservação e organização. Antes de mais, há que distinguir conjuntos documentais que foram incorporados na

${ }^{95}$ Informações em campos "História custodial” " “Organização e ordenação”, na descrição ao nível "fundo" na base de dados Digitarq, no site da DGARQ (http://digitarq.dgarq.gov.pt/).

${ }^{96}$ Campo "História custodial" na descrição ao nível "fundo" na base de dados Digitarq, no site da DGARQ (http://digitarq.dgarq.gov.pt/).

${ }^{97}$ MONTEIRO, Nuno G. - O crepúsculo dos Grandes. A casa e o património da aristocracia em Portugal (1750-1832). Lisboa: IN-CM, 1998, p. 132 e seguintes, re-equacionando a importância do grupo mas reconhecendo uma capacidade de exercer influência e supremacia, em especial na contracção de alianças. 
altura das alianças, bem como os respectivos inventários (que só a eles dizem respeito), e ainda compreender a forma como aqueles foram integrados no circuito documental maior de que passaram fazer parte. Esta é uma questão maior em toda a bibliografia sobre arquivos nobiliárquicos, que propõe diversas soluções ${ }^{98}$. De seguida, e na esteira dos mesmos estudos, há que estabelecer as sucessivas formas de relacionamento dos produtores/ organizadores da informação com esta, em função dos contextos históricos, pois elas condicionam muito a forma de a organizar. Há que estudar os vestígios das sucessivas reorganizações documentais e usos do arquivo - há indícios claros de "interesses legais" (localização, transcrição, re-arrumação de documentos para pleitos e processos) ${ }^{99}$, mas também de algo que se situa entre a curiosidade e a memória histórica/genealógica/erudita. Alguns documentos, que infelizmente se encontram bastante truncados, são verdadeiros compósitos de inventário do arquivo com história da família ${ }^{100}$, em geral começando num e acabando noutra, como se se tornasse evidente que não era possível organizar os papéis sem recorrer à estrutura genealógica que lhe dava sentido. Apesar das delapidações, o arquivo é bastante rico neste tipo de informação, sendo de destacar a existência de alguns inventários, todos eles com o seu interesse específico ${ }^{101}$. O último, que tem a vantagem adicional

${ }^{98}$ Ver as notas 50, 55 e 61. Os trabalhos de António Sánchez González lidam directamente com esta questão, assim como os de Maria José Casaus Ballester, pois ambos estiveram ou estão ligados a arquivos de casas titulares de significativa dimensão.

${ }^{99}$ Ver ANTT - Arquivo dos Viscondes de Vila Nova de Cerveira, cx. 59, doc. 85, "Relação de documentos entregues a D. João Luís de Vasconcelos"(1633); ANTT - Arquivo dos Viscondes de Vila Nova de Cerveira, cx. 32, doc. 34, "Parecer sobre a posse dos morgados por parte de D. João Fernandes de Lima", 1691; ANTT - Arquivo dos Viscondes de Vila Nova de Cerveira, cx. 8, doc. 5, "Parecer sobre o morgado de Gaião", 1649; para além da presença de cópia de alguns dos vários processos, por exemplo, ANTT - Arquivo dos Viscondes de Vila Nova de Cerveira, cx. 18, doc. 1 e cx. 17, doc. 1 - Acção cível entre D. João Luís de Meneses e D. João de Vasconcelos e Meneses sobre morgadio de Soalhães e casa de Mafra, e apenso à mesma; ANTT - Arquivo dos Viscondes de Vila Nova de Cerveira, cx. 40, doc. 1 , "Feito principal da Casa de Mafra, em que são partes os Viscondes de Vila Nova de Cerveira e os condes de Vila Nova".

${ }^{100}$ Por exemplo, ANTT - Arquivo dos Viscondes de Vila Nova de Cerveira, cx. 5, doc. 28, "Papéis tocantes aos dois morgados dos Britos e dos Nogueiras", s.d.; ANTT - Arquivo dos Viscondes de Vila Nova de Cerveira, cx. 2, n $\mathrm{n}^{\mathrm{o}} 9$ e n ${ }^{\circ}$ 10, "Relação de todos os papéis, instituições, mercês e títulos de fazendas e outras mais notícias que se acham no arquivo do excelentíssimo senhor D. Tomás de Lima, Visconde de Vila Nova de Cerveira", sd..

${ }^{101}$ Informações em campo "Organização e ordenação", na descrição ao nível "fundo" na base de dados Digitarq, no site da DGARQ (http://digitarq.dgarq.gov.pt/). 
de estar datado (1819), parece representar todo o conjunto do arquivo numa data muito importante - as vésperas do advento do regime liberal, cuja legislação iria em breve mudar para sempre a vida deste tipo de organismo.

Em suma, a investigação institucional torna-se aqui de grande importância. A instituição família, antes de mais: genealogia da filiação e aliança; a dos cargos desempenhados, depois: não só os directamente jurisdicionais, mas também os políticos, pois o desempenho de algumas funções de Estado deixaram traços marcantes (no que é de novo uma característica comum a muitos destes arquivos) ${ }^{102}$; por fim, a da relação com a administração patrimonial: que propriedades, que expressões territoriais, que corpos a geriam. Depois, há que fazer um esforço de reflexão e de integração dos saberes historiográficos para pensar o organismo produtor e, a partir daí, a sua orgânica. O uso do conceito de "Viscondado" para pensar a entidade que produziu este sistema de informação parece-nos a este respeito bastante operacional - designa uma entidade que não existe no ordenamento societal actual, e que era um misto de relações humanas estruturadas pelo parentesco, bens patrimoniais e direitos jurisdicionais, num conjunto que tinha sentido em si e ultrapassava aqueles que lhe davam corpo, em cada geração. No fundo, uma "casa nobre", neste caso com um título (o que fazia alguma diferença), com tudo o que isso implica em termos de natureza, funcionamento e reprodução - tal como tem sido definido pela historiografia recente ${ }^{103}$. Aqui, de novo, a junção de saberes revela-se fundamental, já que as aquisições daquela permitem ultrapassar visões institucionais anacrónicas, insistindo na importância dos aspectos simbólicos e de poder/saber - e onde melhor situar o arquivo? - para a estruturação destes corpos. O trinómio geração/território/jurisdição parece-nos neste momento muito relevante para definir e organizar a instituição produtora da informação, embora haja ainda um longo caminho de investigação arquivística a percorrer.

${ }^{102} \mathrm{Cfr}$., por exemplo, SÁNCHEZ GONZÁLEZ, Antonio - Los archivos de la nobleza: perspectivas para la investigación in Actas de las Jornadas Archivos e Investigación. Murcia: Ministerio de Cultura - Universidad de Murcia - Caja Murcia, 1996, p. 124-140, categorizando-os como "documentos de «función anexa»" (p. 131-132).

${ }^{103}$ MONTEIRO, Nuno G. - O crepúsculo dos Grandes..., cit., p. 33 e seguintes; no que toca à relação Casa/arquivos, ver por todos, VISCEGLIA, Maria Antonietta - Archivisti e storici..., cit.. 